AIAA 2000-3549

\title{
FACTORS CONTRIBUTING TO PILOT VALVE FUEL SEAL EXTRUSION IN ORBITER PRCS THRUSTERS
}

\author{
J. M. Waller* \\ Honeywell Technology Solutions Incorporated \\ NASA Johnson Space Center White Sands Test Facility \\ Las Cruces, New Mexico
}

\author{
R. L. Saulsberry ${ }^{\dagger}$ \\ NASA Johnson Space Center White Sands Test Facility \\ Las Cruces, New Mexico \\ John D. Albright* \\ NASA Johnson Space Center \\ Houston, Texas
}

\begin{abstract}
$\underline{\text { ABSTRACT }}$
Extrusion of the polytetrafluoroethylene (PTFE) pilot seal used in the monomethylhydrazine (fuel) valve of the Orbiter Primary Reaction Control System (PRCS) thrusters has been implicated in numerous on-orbit thruster failures and on-ground valve failures. Two extrusion mechanisms have been proposed, one or both may be occurring. The first mechanism is attributed to thermal expansion mismatch between adjacent PTFE and metal parts used in the fuel valve, and is referred to as thermal extrusion. The second mechanism is attributed to nitrogen tetroxide (oxidizer) leakage from the adjacent oxidizer valve on the same thruster during ground turnaround, and is referred to as oxidizer-induced extrusion.

Model calculations of PTFE pilot seal in an exact pilot valve configuration show that extrusion can be caused by differential thermal expansion, without the intervening influence of oxidizer. Experimental data on semitrapped PTFE and TFM (modified PTFE) specimens simulating a fuel pilot valve configuration show that thermal extrusion 1) is incremental and irreversible, 2) increases with the size of the thermal excursion, 3) decreases with successive thermal cycling, and 4) is accompanied by gap formation. Both PTFE and TFM exhibit a higher affinity for oxidizer than fuel. The property changes associated with oxidizer uptake may explain why oxidizer seals do not exhibit extrusion.
\end{abstract}

\footnotetext{
* Materials Scientist, NASA-WSTF Laboratories Department

${ }^{\dagger}$ Project Engineer, NASA-WSTF Laboratories Office

* Project Engineer, NASA-JSC Materials Directorate

Copyright (C) 2000 by Honeywell Technology Solutions Incorporated

Published by American Institute of Aeronautics and Astronautics, Inc. with permission.
}

Impression replicas of fuel pilot seals removed from the Orbiter fleet show two types of extrusion: extrusion of the entire seal (loaded extrusion), or extrusion of non-sealing surface (unloaded extrusion). Both extrusion types may arise from differences in service history, rather than in failure mechanism.

The plausibility oxidizer-induced extrusion was evaluated. Preliminary calculations suggest that enough energy, heat, or gas may be liberated under certain operational scenarios to cause catastrophic extrusion. However, given the lack of supporting data, conclusions implicating oxidizer leakage as a factor in extrusion must be made with caution.

\section{INTRODUCTION}

The fuel pilot operated valve (FPOV) controls the flow of fuel to the PRCS injector, where it mixes hypergolically with oxidizer. Each primary thruster is reusable and is certified for 20,000 starts and 12,000 seconds (s) of cumulative firing. Thrusters can be run in a steady state firing mode of one to $150 \mathrm{~s}$, or in a pulse firing mode with a minimum firing time of $80 \mathrm{~ms}$. The valve incorporates a two-stage design: a solenoid actuated pilot stage, which in turn controls a pressure actuated main stage. The fuel supply is isolated from the thruster chamber by a captive PTFE pilot seal inside a Custom 455 (C455) stainless steel cavity. Excessive extrusion of the pilot seal restricts fuel flow around the pilot poppet, thus impeding or preventing the main valve stage from opening.

FPOV seal extrusion has been implicated in two on-orbit Fail-Off anomalies (STS-68 and STS-91), and is suspected in three other on-orbit anomalies (STS-72, STS-72, and STS-83). In addition to on-orbit anomalies, over thirty extruded 
seals have been detected during White Sands Test Facility (WSTF) Depot Acceptance Test Procedures (ATP). ${ }^{\S}$ Similarly, some of the same seals were also found to exhibit low poppet travel as determined by a WSTF Depot Poppet Lift Test."

FPOV seal extrusion has been attributed to two primary mechanisms. ${ }^{1}$ In thermal extrusion, thermal expansion mismatch between adjacent plastic (PTFE) and metal (C455) parts in the valve causes the PTFE seal to extrude gradually out of its cavity over the seal's service lifetime due to heat soak-back from routine thruster firing. The coefficient of thermal expansion (CTE) of PTFE $\left(1.24 \times 10^{-4} \mathrm{~K}^{-1}\right.$ for $\left.\mathrm{T}=298-373 \mathrm{~K}\left(77-212^{\circ} \mathrm{F}\right)^{2}\right)$ is more than one order of magnitude greater than the CTE of $\mathrm{C} 455$ $\left(1.06 \times 10^{-5} \mathrm{~K}^{-1}\right.$ for $\left.\mathrm{T}=294-366 \mathrm{~K}\left(72-200^{\circ} \mathrm{F}\right)^{3}\right)$.

In oxidizer-induced extrusion, migration of oxidizer to the fuel side of the thruster is thought to result in energetic reactions capable of releasing sufficient heat, energy, or gas to cause the seal to extrude out of its cavity during single or multiple thermal event(s). Oxidizer leakage is known to cause pressure build-ups as high as $350 \mathrm{kPa}(50 \mathrm{psia})^{\#}$ inside the thruster chamber during ground turnaround. Pressure build-ups were not a major factor until 1991, when a redesigned throat plug without a vent orifice was put into service. This paper evaluates six oxidizer-related mechanisms:

- Fuel/oxidizer reaction inside PTFE voids.

- Fuel/oxidizer reaction inside seal cavity gaps.

- Fuel/oxidizer reaction at a fuel meniscus.

- Thermally-induced Fuel-Oxidizer Reaction Product (FORP) decomposition.

- Impact-induced FORP detonation.

- FORP-oxidizer reaction.

\section{GOAL AND APPROACH}

The goal was threefold: 1) review historical FPOV failures thought to be caused by extrusion,

$\S$ Cathey, R., WSTF PRCS Thruster Valve Overhaul and Repair Valve Acceptance Test Procedures, WJI-PROP-CTF-0018.D, NASA Johnson Space Center White Sands Test Facility, Las Cruces, NM, September 17, 1999.

^ Kelley, T., WSTF PRCS Thruster Valve Overhaul and Repair Piston Assembly Procedure. WJI-PROP-CTF-0017.E., NASA Johnson Space Center White Sands Test Facility, Las Cruces, NM, January 27, 1999.

\# Unpublished data from Kennedy Space Center, FL. An equilibrium NTO vapor pressure of $350 \mathrm{kPa}$ (50 psia) corresponds to a temperature of $40-45^{\circ} \mathrm{C}\left(104-113^{\circ} \mathrm{F}\right)$.
2) evaluate the plausibility of competing thermal and oxidizer-induced extrusion mechanisms, and 3) test an alternative seal materials. The approach used to evaluate the plausibility of extrusion mechanisms consisted of a combination of service history correlation, model calculations, and experiment. Experiment methods included thermomechanical analysis (TMA), x-ray radiography, hydrostatic liquid immersions, and impression replica methods.

Because of problems associated with conventional PTFE seal materials (poor processibility, cold flow, voids, and extrusion), a so-called 'second generation' modified PTFE (Hostaflon ${ }^{\circledR * *}$ TFM-1700) was evaluated as a possible replacement for DuPont Teflon ${ }^{\text {(1) }}$ 7A PTFE.

\section{EXTRUSION CASES}

Tables 1 and 2 summarize known or suspected FPOV extrusion cases through May 1999 (STS-94). Both mission thruster failures and ground valve failures are listed. PRCS thruster failures have historically occurred during the first hot firing, and have been generally attributed to deposition of metal nitrates between missions within the adjacent Oxidizer Pilot Operated Valve (OPOV), leading to OPOV sticking or leakage. In contrast, extrusion failures may or may not occur during the first firing. For example, the STS-68 thruster S/N 325 mission failure occurred after 399 normal firings (row 1 , Table 1). The two other mission failures listed in Table 1 occurred on the first firing, similar to OPOV failures, however, the associated fuel pilot seals were found later to be extruded. In almost all extrusion cases detected during ATP, the thruster in question underwent numerous successful firings during the last flown mission. Extrusion as little as $13 \mu \mathrm{m}$ (0.005 in.) is generally regarded as being detrimental to Orbiter PRCS thruster performance. ${ }^{4}$

\section{SERVICE HISTORY CORRELATION}

Table 1 lists FPOV seals exhibiting a large increase in the seal proud height as inferred from the WSTF Depot Poppet Lift test. Both older circumferentially-welded (denoted by ' $c$ ') and newer tack-welded (denoted by ' $t$ ') seat assemblies exhibit

\footnotetext{
${ }^{* *}$ Hostaflon ${ }^{*}$ is a registered trademark of Hoechst Aktiengesellschaft.

tt Teflon $^{\otimes}$ is a registered trademark of E. I. DuPont and Nemours and Company.
} 
Table 1. Orbiter Fuel Pilot Operated Valves through STS-94 with Measurable Loaded Extrusion

\begin{tabular}{|c|c|c|c|c|c|c|c|c|c|c|c|c|}
\hline \multirow{2}{*}{$\begin{array}{c}\text { Last } \\
\text { Flown } \\
\text { (STS-) }\end{array}$} & \multirow{2}{*}{$\begin{array}{c}\text { Date } \\
\text { Thruster } \\
\text { Installed }\end{array}$} & \multirow{2}{*}{$\begin{array}{c}\text { Date } \\
\text { Thruster } \\
\text { Removed }\end{array}$} & \multirow[b]{2}{*}{$\begin{array}{c}\text { Position } \\
\text { (\# Missions) }\end{array}$} & \multirow[b]{2}{*}{$\begin{array}{c}\text { Mission } \\
\text { Factor }\end{array}$} & \multirow[b]{2}{*}{$\begin{array}{c}\text { Thruster } \\
\text { S/N }\end{array}$} & \multirow[b]{2}{*}{$\begin{array}{l}\text { Valve } \\
\mathrm{S} / \mathrm{N}^{\mathrm{a}}\end{array}$} & \multicolumn{2}{|c|}{ Last Mission } & \multicolumn{3}{|c|}{ Cumulative } & \multirow[b]{2}{*}{$\begin{array}{c}\text { Extrusion } \\
\text { (mil) }\end{array}$} \\
\hline & & & & & & & Firings & $\begin{array}{c}\text { Ontime } \\
\text { (s) }\end{array}$ & Firings & $\begin{array}{c}\text { Ontime } \\
\text { (s) }\end{array}$ & $\begin{array}{c}\text { Ontime/ } \\
\text { Firing }\end{array}$ & \\
\hline \multicolumn{13}{|c|}{ Mission } \\
\hline 68 & Aug-84 & Nov-95 & R2U(4),L3D(11) & 62.6 & 325 & $530 c$ & 399 & 61 & 6451 & 1040 & 0.92 & $10^{b}$ \\
\hline 76 & Jan-82 & May-96 & R1R(8),R4R(13) & 19.5 & 234 & $528 \mathrm{c}$ & 0 & 0 & 1772 & 754 & 0.43 & $5-7^{c}$ \\
\hline 81 & Apr-81 & Feb-97 & $\mathrm{F} 3 \mathrm{~F}(21)$ & 1.1 & 101 & $254 \mathrm{c}$ & 0 & 0 & 77 & 29 & 0.38 & $9^{c, f}$ \\
\hline 91 & May-91 & Jul-98 & L4D(3),R1U(3),R2U(3) & 12.8 & 628 & $832 t$ & 0 & 0 & 2780 & 386 & 0.14 & $6-8^{d}$ \\
\hline \multicolumn{13}{|c|}{ Fail WSTF ATP Response Tests } \\
\hline 42 & Apr-83 & Jun-92 & $\mathrm{R} 3 \mathrm{~A}(8), \mathrm{L} 1 \mathrm{~A}(8)$ & 2.6 & 217 & $508 \mathrm{c}$ & 15 & 3 & 1269 & 580 & 0.46 & $8-10^{\mathrm{d}}$ \\
\hline 63 & Aug-84 & Mar-95 & R3R(7),L2L(15) & 26.6 & 331 & $544 c$ & 228 & 164 & 2856 & 979 & 0.34 & $6.5^{\mathrm{g}}$ \\
\hline 67 & Oct-87 & Jun-95 & R2R(8),R3R(3) & 12.1 & 476 & $703 t$ & 340 & 88 & 1278 & 365 & 0.29 & $7.5^{\mathrm{g}}$ \\
\hline 70 & Apr-85 & Oct-95 & R4R(3),L1L(15) & 31.9 & 432 & $622 c$ & 5 & 3 & 2994 & 1011 & 0.34 & $7.0^{\mathrm{g}}$ \\
\hline 76 & Feb-89 & May-96 & $\mathrm{R} 4 \mathrm{D}(13)$ & 9.3 & 223 & $548 c$ & 5 & 7 & 128 & 82 & 0.64 & $2-3^{d}$ \\
\hline 77 & May-88 & Oct-96 & $\mathrm{R} 2 \mathrm{D}(6), \mathrm{R} 3 \mathrm{D}(13)$ & 32.9 & 327 & $580 c$ & 654 & 102 & 5648 & 1107 & 0.20 & $7-8^{e, f}$ \\
\hline 77 & May-91 & Jan-97 & $\mathrm{F} 2 \mathrm{~F}(11)$ & 0.6 & 603 & $803 \mathrm{t}$ & 1 & 0 & 637 & 310 & 0.49 & $4-5^{d}$ \\
\hline 77 & May-91 & Jan-97 & $\mathrm{F} 3 \mathrm{~F}(11)$ & 0.6 & 601 & $806 \mathrm{t}$ & 94 & 31 & 145 & 68 & 0.47 & $5-7^{d, f}$ \\
\hline 77 & Oct-91 & Jan-97 & F3U(11) & 15.4 & 571 & $893 t$ & 111 & 13 & 3147 & 477 & 0.15 & $4-5^{d}$ \\
\hline 80 & Apr-84 & Feb-97 & $\mathrm{L} 2 \mathrm{~L}(7), \mathrm{L} 3 \mathrm{~L}(12), \mathrm{R} 2 \mathrm{R}(7)$ & 25.8 & 337 & $594 c$ & 11 & 15 & 2014 & 962 & 0.48 & $3-4^{d}$ \\
\hline 80 & Jun-95 & Feb-97 & $\mathrm{R} 1 \mathrm{U}(4)$ & 14.8 & 325 & $553 \mathrm{t}$ & 1218 & 192 & 2976 & 500 & 0.17 & $6-8^{d}$ \\
\hline 83 & Jul-88 & Apr-97 & $\mathrm{F} 3 \mathrm{D}(15)$ & 4.6 & 305 & $710 \mathrm{t}$ & 7 & 5 & 938 & 320 & 0.34 & $4-5^{\mathrm{d}, \mathrm{f}}$ \\
\hline 86 & Jul-88 & Dec-97 & L4U(17) & 4.9 & 227 & $681 \mathrm{c}$ & 4 & 1 & 114 & 29 & 0.25 & $7-8^{d}$ \\
\hline 86 & Apr-84 & Jan-98 & $\mathrm{L} 1 \mathrm{~A}(7), \mathrm{R} 3 \mathrm{~A}(17)$ & 4.8 & 317 & $584 \mathrm{c}$ & 2 & 1 & 1514 & 1373 & 0.91 & $2-3^{d}$ \\
\hline 86 & Aug-95 & Jan-98 & $\mathrm{R} 2 \mathrm{R}(6)$ & 1.7 & 331 & $718 \mathrm{t}$ & 39 & 24 & 78 & 61 & 0.78 & $3-4^{d}$ \\
\hline \multicolumn{13}{|c|}{ Pass WSTF ATP Response Tests } \\
\hline 63 & Jun-89 & Mar-95 & R1U(12) & 44.5 & 497 & $744 t$ & 0 & 0 & 5252 & 1008 & 0.19 & $5.5^{\mathrm{g}}$ \\
\hline $\begin{array}{l}\text { a 'c' an } \\
\text { b See V } \\
\text { c Missi } \\
\text { d Inferr } \\
\text { e Inferr } \\
\text { f Impre } \\
\text { g See R }\end{array}$ & $\begin{array}{l}\text { ' } t \text { ' denote } \\
\text { STF PT-F } \\
\text { failure d } \\
\text { ed from WS } \\
\text { ed from WS } \\
\text { sion replic } \\
\text { I Downey I }\end{array}$ & $\begin{array}{l}\text { ircumferer } \\
\text { R3-002 (R } \\
\text { to OPOV } \\
\text { F poppet } 1 \\
\text { F poppet } 1 \\
\text { made (bo } \\
\text { PR 5965-2 }\end{array}$ & $\begin{array}{l}\text { al and tack welds, respecti } \\
\text { S, Lynch, and Pfeiffer } 199 \\
\text { ail-leak anomaly. } \\
\text { test, extrusion detected du } \\
\text { test, extrusion detected du } \\
\text { valve S/N), see Section } 6 . \\
7 \text { (Litwinski, Swene, and }\end{array}$ & $\begin{array}{l}\text { g ATP } \\
\text { h ATP } \\
\text { his repor } \\
\text { ttman } 19\end{array}$ & $\begin{array}{l}\text { bmitted } t \\
\text { bmitted t }\end{array}$ & $\begin{array}{l}\text { VSTF } \\
\text { TF du }\end{array}$ & $\begin{array}{l}\text { nponent } \\
\text { OPOV }\end{array}$ & $\begin{array}{l}\text { est Facil } \\
\text { k). }\end{array}$ & for pre & tive mai & ance wo & flushing). \\
\hline
\end{tabular}


Table 2. Orbiter Fuel Pilot Operated Valves through STS-94: Unloaded Extrusion or Extrusion Not Measured

\begin{tabular}{|c|c|c|c|c|c|c|c|c|c|c|c|c|}
\hline \multirow{2}{*}{$\begin{array}{l}\text { Last } \\
\text { Flown } \\
\text { (STS-) }\end{array}$} & \multirow{2}{*}{$\begin{array}{c}\text { Date } \\
\text { Thruster } \\
\text { Installed }\end{array}$} & \multirow{2}{*}{$\begin{array}{c}\text { Date } \\
\text { Thruster } \\
\text { Removed }\end{array}$} & \multirow[b]{2}{*}{$\begin{array}{c}\text { Position } \\
\text { (\# Missions) }\end{array}$} & \multirow[b]{2}{*}{$\begin{array}{l}\text { Mission } \\
\text { Factor }\end{array}$} & \multirow[b]{2}{*}{$\begin{array}{c}\text { Thruster } \\
\mathrm{S} / \mathrm{N}\end{array}$} & \multirow[b]{2}{*}{$\begin{array}{l}\text { Valve } \\
\mathrm{S} / \mathrm{N}^{\mathrm{a}}\end{array}$} & \multicolumn{2}{|c|}{ Last Mission } & \multicolumn{3}{|c|}{ Cumulative } & \multirow[b]{2}{*}{$\begin{array}{l}\text { Extrusion } \\
\text { (mil) }\end{array}$} \\
\hline & & & & & & & Firings & $\begin{array}{l}\text { Ontime } \\
(\mathrm{s})\end{array}$ & Firings & $\begin{array}{l}\text { Ontime } \\
(\mathrm{s})\end{array}$ & $\begin{array}{l}\text { Ontime/ } \\
\text { Firing }\end{array}$ & \\
\hline \multicolumn{13}{|c|}{ Mission - Possible Unloaded Extrusion } \\
\hline 72 & Jul-92 & Feb-96 & $\mathrm{L} 1 \mathrm{~A}(6)$ & 1.2 & 574 & $895 \mathrm{t}$ & 0 & 0 & 26 & 69 & 2.65 & $0-1^{\mathrm{b}}$ \\
\hline 83 & Jan-86 & Mar-97 & $\mathrm{F} 3 \mathrm{~F}(16)$ & 0.8 & 451 & $672 c$ & 0 & 0 & 70 & 53 & 0.76 & $1-2^{b}$ \\
\hline \multicolumn{13}{|c|}{ Fail WSTF ATP Response Tests - Possible Unloaded Extrusion } \\
\hline 70 & Apr-88 & Nov-95 & $\mathrm{F} 3 \mathrm{U}(21)$ & 8.4 & 108 & $679 c$ & 296 & 42 & 1766 & 322 & 0.18 & $0^{\mathrm{b}, \mathrm{d}}$ \\
\hline 76 & Apr-84 & May-96 & $\begin{array}{l}\mathrm{L} 2 \mathrm{U}(3), \mathrm{L} 3 \mathrm{D}(7), \mathrm{R} 2 \mathrm{D}(9) \\
\mathrm{L} 2 \mathrm{D}(4)\end{array}$ & 2.9 & 125 & $604 c$ & 131 & 22 & 541 & 105 & 0.19 & $0^{\mathrm{b}}$ \\
\hline 77 & Apr-85 & Dec-96 & $\mathrm{R} 2 \mathrm{D}(3), \mathrm{L} 4 \mathrm{D}(15)$ & 3.0 & 422 & $586 c$ & 1 & 6 & 205 & 163 & 0.80 & $0^{b, e}$ \\
\hline 80 & Jun-83 & Mar-97 & $\mathrm{L} 2 \mathrm{D}(7), \mathrm{R} 3 \mathrm{D}(9), \mathrm{R} 4 \mathrm{D}(4)$ & 27.4 & 421 & $582 \mathrm{c}$ & 5 & 7 & 3791 & 725 & 0.19 & $0^{\mathrm{b}}$ \\
\hline 81 & Mar-83 & Feb-97 & F3L (14) & 16.4 & 411 & $637 c$ & 197 & 42 & 2181 & 736 & 0.33 & $0^{\mathrm{b}, \mathrm{d}}$ \\
\hline 81 & Jun-85 & Mar-97 & L2L(3),L1L(6),R4R(2) & 14.6 & 437 & $600 c$ & 16 & 13 & 1702 & 655 & 0.38 & $0^{\mathrm{b}}$ \\
\hline 86 & Apr-83 & Jan-98 & L4D(8),L2D(9),L1U(8) & 30.0 & 229 & $552 \mathrm{c}$ & 170 & 25 & 4193 & 770 & 0.18 & $0^{\mathrm{b}}$ \\
\hline 86 & Apr-83 & Dec-97 & R4R(8),L4L(17) & 11.1 & 237 & $543 c$ & 46 & 27 & 1249 & 418 & 0.33 & $0^{\mathrm{b}}$ \\
\hline 86 & Aug-84 & Jan-98 & R4R(7),R2R(10),R1R(8) & 18.4 & 332 & $569 c$ & 7 & 5 & 1230 & 608 & 0.49 & $0^{\mathrm{b}}$ \\
\hline 86 & Aug-84 & Dec-97 & R1R(7),R3R(14),L2L(4) & 57.8 & 335 & $575 \mathrm{c}$ & 161 & 46 & 5837 & 1775 & 0.30 & $0^{\mathrm{b}}$ \\
\hline \multicolumn{13}{|c|}{ Fail WSTF ATP Response Tests - Extrusion not Measured } \\
\hline 70 & Apr-83 & Oct-95 & R4U(8),R1U(2),R3D(11) & 48.1 & 220 & $516 \mathrm{t}$ & 472 & 75 & 6720 & 1230 & 0.18 & $\mathrm{NA}^{\mathrm{c}}$ \\
\hline 70 & Jul-88 & Oct-95 & R4U(6),L1U(14),R1U(1) & 18.6 & 330 & $714 t$ & 739 & 93 & 3866 & 877 & 0.23 & $\mathrm{NA}^{\mathrm{c}}$ \\
\hline 77 & Apr-81 & Dec-96 & L2D(6),L2U(5),L2D(7) & 6.4 & 126 & $263 c$ & 187 & 43 & 1107 & 243 & 0.22 & $N^{c}$ \\
\hline 77 & Apr-81 & Dec-96 & R2R(6),L3L(15) & 31.5 & 133 & $255 \mathrm{c}$ & 52 & 11 & 2034 & 721 & 0.35 & $\mathrm{NA}^{\mathrm{c}}$ \\
\hline 77 & Jun-85 & Dec-96 & $\mathrm{L} 2 \mathrm{U}(3), \mathrm{R} 2 \mathrm{U}(9), \mathrm{L} 3 \mathrm{D}(4)$ & 24.4 & 430 & $588 \mathrm{c}$ & 743 & 108 & 2979 & 442 & 0.15 & $\mathrm{NA}^{\mathrm{c}}$ \\
\hline \multicolumn{13}{|c|}{$\begin{array}{l}\text { Negligible loaded extrusion as measured by poppet lift test (less sensitive to unloaded extrusion). } \\
\text { NA denotes poppet lift data not available. Extrusion inferred from } \mathrm{GN}_{2} \text { and } \mathrm{H}_{2} \mathrm{O} \text { opening response times. } \\
\text { Pronounced unloaded extrusion as measured by impression replica technique (bold valve S/N), see Section 8.4, this report. } \\
\text { e Submitted to CTF due to FPOV leak. }\end{array}$} \\
\hline
\end{tabular}


this type of extrusion, henceforward referred to as loaded extrusion. Table 2 lists FPOV seals exhibiting little or no change in the seal proud height as inferred from the WSTF Poppet Lift test, but which were nevertheless suspected of extrusion due to high response times measured during WSTF ATP. All of the valves that failed ATP response tests performed normally during prior flight service. ATP response testing thus was able to detect and screen out extruded valve seals whose performance had not yet degraded during service. Although little or no loaded extrusion was indicated, representative impression replicas later showed a large increase in the height of the unloaded portion of the pilot seal. This type of extrusion is henceforward referred to as unloaded extrusion.

While almost all of the pilot seats exhibiting unloaded extrusion were circumferentially-welded, only about half of the pilot seats exhibiting loaded extrusion were circumferentially-welded. Since fuel migration into the pilot seal cavity and subsequent reaction with oxidizer is less plausible for circumferentially-welded pilot seats, it is tempting to ascribe unloaded extrusion to thermal cycling effects. By corollary, tack-welded pilot seal exhibiting loaded extrusion would be thought to due to the presence of oxidizer. However, factors such as the variation of the cumulative loading and temperature profile could explain the observed distribution of unloaded versus loaded extrusion cases.

A clearer understanding of premature failures could reveal the factors behind seal extrusion. Service histories of prematurely-extruded seals were thus examined. Inspection of Tables 1 and 2 shows that valve S/N 254 (77 firings, 9 mil loaded extrusion), valve S/N 681 (114 firings, 7-8 mil loaded extrusion), valve S/N 895 (26 firings, unloaded extrusion), and valve $\mathrm{S} / \mathrm{N} 672$ (70 firings, unloaded extrusion) all failed prematurely. Fuel valve S/N 895, which had the lowest number of cumulative firings, also had the highest ontime/firing ratio ( $2.65 \mathrm{~s} /$ firing). Other entries in Table 2 with low cumulative firings also failed with relatively high ontime/firing ratio (valve S/Ns 586 and 672).

This suggests that steady-state mode burns may be a factor in unloaded extrusion. In contrast, the ontime/firing ratio does not appear to be linked to the incidence of premature failure for Table 1 loaded extrusion cases. For example, valve S/N 530, which had the highest ontime/firing ratio (0.92 s/firing), failed with the highest number of cumulative firings (6451). A scatter plot of Table 1 (loaded) extrusion values against the ontime/firing ratio gave an $R^{2}$ of 0.06 (no correlation). There was no correlation between extrusion and number of thruster firings, thruster ontime, mission factor, or thruster position. Correlation of extrusion with other service history parameters such as multiple burns, time at temperature, and throat plug (oxidizer leakage) history could be more revealing, but had not yet been undertaken at the time of this paper.

\section{EXPERIMENTAL}

Materials. DuPont Teflon 7A (T-7A) PTFE (non-free-flowing compression molding grade, EGC Corp., Houston, TX), Teflon 9B (T-9B) PTFE (freeflowing extrusion grade, McMaster Carr, Los Angeles, CA), and Hostaflon TFM ${ }^{5,+\$} 1700$ (non-freeflowing modified PTFE, obtained from EGC Corp., Houston, TX) were obtained as rod stock with diameters, $d$, of $47.6 \mathrm{~mm}$ (1.875 in.), $6.4 \mathrm{~mm}(0.25$ in.), and $24 \mathrm{~mm}$ (0.95 in.), respectively. C455 (Metal Profiles, Inc.) was obtained as rod stock with $d=34.9$ $\mathrm{mm}$ (1.375 in.). All test materials were used as received. Fuel and oxidizer met MIL-PRF-27404 and NASA SE-S-0073 specifications, respectively, and were obtained on site. T-7A is currently used in PRCS thruster pilot and main seal fabrication and is procured under Marquardt specification MMS2517. ${ }^{6}$ By comparison, the procurement specification for the EGC T-7A was AMS 3660. ${ }^{7}$ The specifications for the T-9B, TFM 1700, or C455 were not known.

Specimen Preparation. Steps were taken to minimize frictional heating of T-7A, T-9B, and TFM1700 during machining (lathe surface speeds $<500$ fpm). Cylindrical PTFE and TFM specimens had $d=$ $4.93 \pm 0.0025 \mathrm{~mm}(0.194 \pm 0.001 \mathrm{in}$.), so that insertion into the $\mathrm{C} 455$ sleeve (axial bore of $0.476 \mathrm{~mm}$ (0.1875 in.)) gave an interference fit (percent squeeze) of 7 to 9 percent. Kaiser Marquardt uses an interference fit of 1 to 7 percent during fabrication of pilot seats. This range of compression is the minimum feasible using reasonable production tolerances on mating metal parts. ${ }^{\S \S}$ Since the upper limit for the interference fit was used in this study, the TMA results are skewed towards the maximum extrusion expected for pilot POV seals, ignoring the specimen

\footnotetext{
\# TFMs are claimed to be chemically inert, impermeable (low void content), fusible using conventional thermoforming techniques, and resistant to cold flow, and are therefore considered as possible replacements for currently used PTFEs.

$\S \S$ Wichmann, H. (consultant) TFE Seat Evolution Report. ISC Report 90201, PO T-92270, NASA Johnson Space Center White Sands Test Facility, Las Cruces, NM, February 1999.
} 
geometry differences (cylinder versus an actual seal with a "L"-shaped cross-section).

TMA Expansion Fixture. To simulate an actual pilot seal, a TMA expansion fixture was designed such that semitrapped, cylindrical specimens had the same exit area-to-constrained area ratio as an actual pilot seal. It was not practical to fabricate specimens with the same exit area-to-constrained volume ratio as an actual seal, since the resulting geometry would have been incompatible with the TMA cell and probe. A more detailed description of design of the TMA expansion fixture is given elsewhere. $^{8}$

Thermomechanical Analysis. The effects of metal constraint, thermal cycling, and propellant exposure on PTFE and modified PTFE extrusion were assessed by TMA. Properties such as the CTE, room temperature modulus, and permanent (nonrecoverable) extrusion were measured using a Seiko (now Haake Fisons) Model 120C Thermomechanical Analyzer equipped with liquid nitrogen cooling. Analyses included determining the 1) room temperature modulus at $25.0 \pm 0.2{ }^{\circ} \mathrm{C}$ using a $0.05 \mathrm{~Hz}, 15 \pm 10 \mathrm{~g}(7700 \pm 5100 \mathrm{~Pa}(1.12 \pm 0.74 \mathrm{psi}))$ oscillating load, ${ }^{, \pi}$ ) 2 phase transition onset (PTFE hexagonal-triclinic phase transition), 3) average and point CTEs using a programmed $5^{\circ} \mathrm{min}^{-1}$ heating ramp and a $10 \mathrm{~g}(5100 \mathrm{~Pa}(0.74 \mathrm{psi}))$ static load. $^{\text {(II }}$ The effect of the size of the thermal excursion $(\Delta \mathrm{T})$ on permanent extrusion of semi-trapped PTFE was measured by cyclic heating $\left(5^{\circ} \mathrm{C} \mathrm{min}{ }^{-1}\right.$ rate $)$ and cooling $\left(20^{\circ} \mathrm{C} \mathrm{min}^{-1}\right.$ rate $)$ with programmed $\Delta \mathrm{Ts}=60$, 110 , and $145^{\circ} \mathrm{C}\left(108,189\right.$ and $\left.261^{\circ} \mathrm{F}\right)$.

Propellant Immersions. Series immersions were conducted at $71^{\circ} \mathrm{C}\left(160^{\circ} \mathrm{F}\right)$ using NASASTD-6001 Test $15^{9}$ temperature control baths equipped with pressure and temperature data acquisition. T-9B specimens were subjected to a 2week fuel immersion, followed immediately by a 2 week oxidizer immersion. Hydrostatic pressures during Test 15 immersions were about $180 \mathrm{kPa}$ (26 psia) for fuel, and $890 \mathrm{kPa}$ (130 psia) for oxidizer.

Parallel immersions were conducted at room temperature using Fisher-Porter bottles (oxidizer), or screw-cap glass vials (fuel). T-7A and TFM-1700 specimens were immersed in fuel for 4 weeks, or oxidizer for 7 weeks. The effect of fuel and oxidizer on the mass, dimensions and modulus of PTFE and

\footnotetext{
โI Valid for as-machined specimens with a $19.1 \mathrm{~mm}^{2}\left(0.0296 \mathrm{in.}^{2}\right)$
} cross-sectional area.
TFM specimen was then determined. All fuel manipulations were conducted under nitrogen. Masses and Dimensions. Mass determinations were performed in triplicate to the nearest $0.0001 \mathrm{~g}$ immediately after removal from liquid propellant by placing specimens in gas-tight petri dishes. Specimen height and diameter were measured immediately thereafter in triplicate to the nearest $0.01 \mathrm{~mm}$ using a Mitutoyo model IDC-1012ME dial micrometer.

Impression Replicas. Impression replicas of the sealing side of the pilot poppet POV seats (Marquardt P/N 235681 or 234158-504) listed in Table 3 were cast using Reprorubber Thin Pour \#16135 (FlexBar Machine Corp., Islandia, NY). POV seal heights were measured in triplicate using a Leco 300 Metallograph equipped with a Mitutoyo Model ID-C125EB precision $x-y$ recorder with 1-0.00005 in. $(25.4-0.0001 \mathrm{~mm})$ resolution. All proud height measurements were made at 32 to $63 \times$ magnification under polarized light.

Table 3. Valve Seat ${ }^{\mathrm{a}}$ Impression Replicas

\begin{tabular}{|c|c|c|c|}
\hline $\begin{array}{l}\text { Valve } \\
\text { S/N }\end{array}$ & $\begin{array}{l}\text { Seat } \\
\mathrm{S} / \mathrm{N}\end{array}$ & $\begin{array}{l}\text { Extrusion } \\
\text { Type }\end{array}$ & Description \\
\hline 254 & 3040 & loaded & fuel, Orb \\
\hline 553 & 3386 & & \\
\hline 580 & 05 & & \\
\hline 806 & 3372 & & \\
\hline 637 & 2040 & unloaded & fue \\
\hline 679 & 2026 & unlo & \\
\hline as-built ${ }^{\mathrm{b}}$ & 152 & unloaded & fuel, control \\
\hline as-built ${ }^{\mathrm{b}}$ & 2054 & pure thermal & fuel, WSTF Depot ${ }^{\mathrm{c}}$ \\
\hline as-built ${ }^{b}$ & 3203 & unextruded & unused, control \\
\hline \multicolumn{4}{|c|}{$\begin{array}{l}\left.{ }^{a} \text { Manufactured by Kaiser Marquardt (P/N } 235681 \text { or } 234158-504\right) \text {. } \\
\text { b }\end{array}$} \\
\hline \multicolumn{4}{|c|}{${ }^{\mathrm{E}}$ Extruded during WSTF Depot lock collar weld procedure. } \\
\hline \multicolumn{4}{|c|}{$\begin{array}{l}\text { analysis of a semitrapped T-9B PTFE cylinder inside a } \\
\mathrm{C} 455 \text { sleeve subjected to cyclic heating from } 40 \text { to } \\
140{ }^{\circ} \mathrm{C} \text { was accomplished using a Be window, } 90 \mathrm{kV} \\
\text { accelerating potential, and high contrast Kodak type }\end{array}$} \\
\hline
\end{tabular}

\section{RESULTS AND DISCUSSION}

\section{$\underline{\text { General Comments on Oxidizer-Induced Extrusion }}$}

Oxidizer-induced extrusion can be broken down into two categories: 1) fuel/oxidizer ( $\mathrm{Fu} / \mathrm{Ox}$ ) 
reaction, and 2) FORP reaction (including detonation and decomposition). The plausibility of $\mathrm{Fu} / \mathrm{Ox}$ reactions contributing to extrusion was evaluated by calculating the amount of energy, heat, or gas released by a worst-case stoichiometric reaction. However, several uncertainties cloud resolution of the extrusion issue from a Fu/Ox reaction standpoint. The uncertainties are: 1) unknown transmission rate of propellants through fuel pilot seal, 2) reaction stoichiometry, rate and duration, and 3) reaction location. Because of these uncertainties, statements implicating the $\mathrm{Fu} / \mathrm{Ox}$ reactions as a contributing factor in FPOV extrusion should be made with caution and considered tentative.

Calculating the amount of energy, heat, or gas released by FORP reactions was not possible due to uncertainties about the underlying FORP thermochemistry. More specifically, very little is known about 1) the source of FORP (produced by oxidizer leakage or routine thruster firing), 2) the composition and reactivity of FORPs (depends on whether produced on-ground versus on-orbit), and 3 ) the presence or absence of FORP inside the seal cavity. ${ }^{8}$ Because of these uncertainties, statements implicating the FORP as a contributing factor in FPOV extrusion should also be made with caution and considered tentative.

With these caveats in mind, the plausibility of FORP detonation was evaluated by comparing the amount of energy required to initiate detonation or with the amount of energy associated with poppet impact. Similarly, the plausibility of FORP decomposition was evaluated by comparing the amount of heat required to initiate decomposition with the amount of heat associated with soak-back after thruster firing. The plausibility of FORP reaction with oxidizer vapor was simply based on previous reports of hydrazine FORP-liquid oxidizer reactivity. ${ }^{10}$

\section{Fu/Ox Reaction-Induced Extrusion}

PTFE Void Reaction. The temperature rise, $\Delta q$, of a pilot seal after a worst-case stoichiometric fuel-oxidizer reaction inside the interstitial voids of the PTFE seal was calculated as:

$$
\Delta q=\frac{V_{F u} \times \rho_{F u}}{M_{F u}} \times \Delta H_{f}=\frac{0.05 \times V_{s e a l} \times \rho_{F u}}{2.25 \times M_{F u}} \times \Delta H_{f}
$$

where $V_{F u}$ was the volume of fuel inside the pilot POV seal, $\rho_{F u}$ was the fuel density $\left(0.8702 \mathrm{~g} \mathrm{~cm}^{-3}\right), M_{F u}$ was the fuel molar mass $\left(46.07 \mathrm{~g} \mathrm{~mol}^{-1}\right), V_{\text {seal }}$ was the volume of the pilot seal $\left(2.02 \times 10^{-2} \mathrm{~cm}^{-3}\right)$, and 0.05 and 3.5 were factors to account for the void space and stoichiometry, respectively. Solution of Equation 1 gave $\Delta q=9.8 \times 10^{-3} \mathrm{~kJ}\left(2.3 \times 10^{-3} \mathrm{kcal}\right)$. Knowledge of the heat capacity $\left(C_{P T F E}=1.2 \mathrm{~kJ} \mathrm{~kg}^{-1} \mathrm{~K}^{-1}\right)$ and density $\left(\rho_{F u}=2.14\right)$ of PTFE gave the associated heat rise of the seal, $\Delta T_{\text {seal }}$;

$$
\Delta T_{\text {seal }}=\frac{\Delta q}{C_{P} \times \rho_{\text {PTFE }} \times V_{\text {seal }}}
$$

was about $185^{\circ} \mathrm{C}\left(365^{\circ} \mathrm{F}\right)$. The corresponding amount of gas liberated was about 6 times the POV seal volume. While the amounts of heat and gas liberated are appreciable, the amounts are unrealistic for several reasons. First, a solid state reaction inside seal voids would be mass transport-, not kinetic-controlled, leading to lower rates of heat and gas liberation. Second, dissipation of heat into surrounding metal would lower seal temperature rise. Third, the likelihood of a stoichiometric reaction occurring in a fuel-rich environment such as the fuel valve would be remote. Fourth, observation of a fuel meniscus downstream of the seal cavity ${ }^{\# \#}$ suggests that oxidizer would be consumed before getting into the seal cavity. Fifth, the nominal 264 psia MMH pressure gradient operating across the pilot seal would be expected to prevent migration of oxidizer into the fuel pilot seal cavity.

Seal Cavity Gap Reaction. Gaps located in the seal cavity have been proposed as an alternate site for fuel-oxidizer reaction. Such gaps have been observed in the FPOV seal cavity in thruster $\mathrm{S} / \mathrm{N} 530^{1,4}$ (Figure 1) and thruster S/N 703. ${ }^{1}$ Such gaps may be preexisting (produced during fabrication), or may form during service (produced by detonation or differential thermal expansion). Regardless of the gap origin, knowledge of the gap volume is informative. Assuming the gap beneath the vertical leg of the FPOV seal in Figure 1 is circumferential, the volume would be of the order of $10^{-4} \mathrm{~cm}^{3}\left(10^{-5} \mathrm{in}^{3}\right)$, or about 5 percent of the seal volume. A stoichiometric $\mathrm{Fu} / \mathrm{Ox}$ reaction could then produce a temperature rise and gas release comparable to that calculated above. However, the plausibility of this scenario is plagued by the same shortcomings mentioned in the previous paragraph.

Fuel Meniscus Reaction. A more plausible $\mathrm{Fu} / \mathrm{Ox}$ reaction may involve reaction of a fuel

\footnotetext{
\#\# Inspection of PRCS thrusters with a boroscope has revealed the presence of a fuel meniscus downstream of the seal cavity, T. Lucht, private communication, White Sands Test Facility, Las Cruces, NM, 1999.
} 
meniscus with oxidizer vapor with along the inner diameter (proud height) edge of the pilot seal (Figure 2 ). Since a typical seal proud height, $X_{\text {proud }}$, is about $0.013 \mathrm{~cm}$ (0.005 in.), and assuming a meniscus with an approximate half hemispherical cross-section having $\mathrm{r}=\mathrm{x}_{\text {proud }}$, and $\mathrm{R}=0.1416 \mathrm{~cm}(0.05575 \mathrm{in}$.$) , the$ volume of a $360^{\circ}$ circumferential meniscus would be:

$$
V_{\text {meniscus }} \approx \frac{1}{4} \times 2 \pi^{2} R r^{2}
$$

or $1.2 \times 10^{-4} \mathrm{~cm}^{3}\left(7 \times 10^{-6}\right.$ in. $\left.^{3}\right)$, which in turn corresponds to $2.2 \times 10^{-6} \mathrm{~mol}$ of fuel. For a worst case reaction of this fuel meniscus with oxidizer vapor under similar conditions to those mentioned above (stoichiometric, quantitative, and instantaneous), $\Delta \mathrm{T}_{\text {seal }}$ would be about $50^{\circ} \mathrm{C}\left(120^{\circ} \mathrm{F}\right)$. Considering the possibility that the 1) the meniscus could be replenished by upstream fuel forced through the seal by the pressure gradient, and 2) the heat of reaction may be dissipated into a more localized area near the sealing surface, the actual temperature rise could be higher or of longer duration, resulting in more extrusion.

\section{FORP Reaction-Induced Extrusion}

FORP Decomposition. Several arguments challenge the plausibility of thermally-induced FORP decomposition. First, thermally-induced FORP decomposition is unlikely to occur as a result of heat soak-back from normal thruster firing since the temperatures reached are lower than the onset of decomposition as determined by Differential Scanning Calorimetry (DSC). ${ }^{10,11}$ Second, the effect of a fuel pressure gradient operating across the pilot seal, coupled with the observation of a fuel meniscus along the downstream edge of the pilot seal, suggests that oxidizer would be consumed downstream of the fuel pilot seal, preventing FORP formation inside the pilot seal cavity. In fact, the authors are not aware of any data that shows conclusively the presence of FORP in the pilot seal cavity.

FORP Detonation. Observation of gaps in the seal cavity has lead to the hypothesis that the gaps were produced by an energetic event such as FORP detonation that pushed the pilot seal out of its cavity. ${ }^{4}$ The possibility of FORP detonation is inconsistent with the presence of a fuel meniscus, however, since this would prevent accumulation of FORP in the pilot seal cavity. The upward dislocation of the pilot seal in valve S/N 530 (Figure 1) appears to be more indicative of a uniform thermal event affecting the entire seal, not just part of the seal as would presumably be the case for a more localized energetic event. Preliminary calculations ${ }^{8}$ further weaken the plausibility of impact-induced FORP detonation. The poppet impact energy associated with a worst case 8.3 MPa (1200 psi) pilot poppet water hammer is less than the reported impact sensitivity of FORP. ${ }^{10,12}$ Other investigators have found FORP to be together insensitive to impact. ${ }^{11}$ Poppet impact thus does not appear to be energetic enough to cause detonation.

FORP-Oxidizer Reaction. A review of the available literature reveals that hydrazinium nitrate reacts vigorously with liquid oxidizer at temperatures as low as $-60^{\circ} \mathrm{C}\left(-140^{\circ} \mathrm{F}\right) .^{10}$ It is then plausible that FORP residues containing methylhydrazinium nitrate could react with oxidizer vapor to produce significant heating.

\section{Thermal Extrusion}

Thermal Expansion Model. To assess the plausibility of thermal extrusion, a model was developed to allow calculation of the extrusion of a semitrapped PTFE PRCS pilot seal as a function of $\Delta \mathrm{T}$. The assumptions, derivation, and possible improvements to the model are discussed elsewhere. ${ }^{8}$ The model allowed the net extrusion, $\Delta l_{n e}$, to be calculated as:

$$
\Delta l_{n e t}=\frac{\Delta V}{\pi\left(r_{o d}^{2}-r_{i d}^{2}\right)}
$$

where $\Delta V$ was the change is the unconstrained volume of the PTFE pilot seal corrected for metal cavity expansion, and $r_{o d}$ and $r_{i d}$ were the outer and inner radii of the seal exit surface. To account for partial poppet coverage (reduced escape area), $r_{\text {poppet }}$ was substituted for $r_{i d}$ in Equation 4.

The calculated net extrusion was then compared to measured extrusion (Figure3) determined by taking 'hot' impression replicas heated POV seat assemblies heated to 71,102 , and $121^{\circ} \mathrm{C}(160,215$, and $\left.250^{\circ} \mathrm{F}\right) .^{13}$ To simulate poppet loading, some of the POV seat assemblies were loaded with a mock poppet weighing $25 \mathrm{~N}\left(5.6 \mathrm{lb}_{\mathrm{f}}\right)$ (solid circles). The agreement is good, especially between the predicted loaded extrusion (dotted line), and the lower temperature 71 and $102^{\circ} \mathrm{C}\left(160\right.$ and $\left.215^{\circ} \mathrm{F}\right)$ impression replica data.

Despite uncertainty in the measured data attributable to taking replicas of hot pilot seats as they cooled, the impression replica data suggests that poppet loading had little effect on extrusion at 
temperatures at or below $102^{\circ} \mathrm{C}\left(215^{\circ} \mathrm{F}\right.$ ) (note the overlapping of loaded and unloaded data points). This observation reinforces the notion that extrusion at lower temperatures is manifested as loaded extrusion (negligible seal distortion by poppet). This notion is further supported by the fact that the compressive yield strength of PTFE is $4.8 \mathrm{MPa}(700 \mathrm{psi})$ at $65^{\circ} \mathrm{C}$ $\left(150^{\circ} \mathrm{F}\right),{ }^{4}$ and $11.0 \mathrm{MPa}(1600 \mathrm{psi})$ at $25^{\circ} \mathrm{C}\left(77^{\circ} \mathrm{F}\right) .^{6}$ In nether instance, would the compressive yield strength of the seal be exceeded by the compressive stress of $7.9 \mathrm{MPa}(1150 \mathrm{psi})$ due to $25 \mathrm{~N}\left(5.6 \mathrm{lb}_{\mathrm{f}}\right)$ poppet loading at 50 percent poppet coverage.

The impression replica data do diverge at $121^{\circ} \mathrm{C}\left(250^{\circ} \mathrm{F}\right)$, reinforcing the notion that extrusion at higher temperatures is manifested as unloaded extrusion (significant seal distortion by the poppet). To the extent that this is true, permanent seal deformation, coupled with increased extrusion, should become more increasingly important at higher on-orbit thruster temperatures. However, it can not be ruled out that at least part of this divergence is due to the extra thermal shrouding provided by the mock poppet.

It is interesting to note that the STS-68 failure was blamed on a single catastrophic event that 'pushed' the entire seal out of its cavity (Figure 1). This argument seemed plausible, since the authors argued, poppet action should have resulted in a deeper "footprint" than was observed. The authors of this study propose an alternate explanation for the failure mode shown in Figure 1. Namely, repeated excursions to temperatures of the order of $32-37^{\circ} \mathrm{C}$

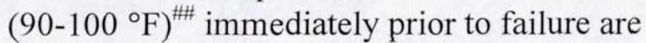
insufficiently high to cause the compressive yield strength of the seal to be exceeded by the compressive stress from poppet loading, therefore preventing a deeper "footprint" from forming. Consequently, the gross extrusion evidenced in Figure 1 is more likely a consequence of gradual rather than catastrophic extrusion.

Incomplete Recovery. It is important to note that the extrusion calculated in Equation 4 is the net extrusion. During cooling, only part of the net extrusion is recoverable, while the remainder is nonrecoverable. Only the nonrecoverable portion contributes to permanent extrusion. Understanding the recovery process during cooling is critical if

\footnotetext{
\#\# The temperature downstream of the pilot seal during the STS-68 failure as measured by a system thermocouple did not detect temperatures above $95^{\circ} \mathrm{F}\left(35^{\circ} \mathrm{F}\right)$ during the approximately 80 thruster pulses spanning the $10 \mathrm{~h}$ before thruster failure.
}

predictions are to be made about the long-term performance of PRCS pilot seals in service.

The amount of recovery can be estimated by comparing the total extrusion measured while hot with the residual extrusion measured after cooling. Using previous data, ${ }^{13}$ the recovery of mock poppet-loaded and unloaded pilot seals heated to $121^{\circ} \mathrm{C}\left(250^{\circ} \mathrm{F}\right)$, and subsequently cooled to room temperature, was 67 and 61 percent, respectively. This suggests that poppet loading may assist in the recovery process, however, recovery of an actual PRCS pilot seal was far from complete in either the poppet-loaded or unloaded case after a large thermal excursion.

The most immediate ramification of incomplete recovery for PRCS pilot seals is obvious: incremental extrusion. Incremental extrusion in turn is expected to cause the seal to gradually "walk out" of its cavity, consistent with one of the failure modes initially proposed in $1996 .^{1}$ There is also another less obvious ramification. In order to conserve seal mass, a gap must also form in the seal cavity to compensate for lost material (assuming constant seal density, crystallinity, etc.). TMA data and x-ray radiography data are presented in support of incremental extrusion and accompanying gap formation. Other factors thought to affect incremental extrusion but not specifically addressed in this paper are:

$$
\begin{aligned}
& \text { - } \quad \text { poppet loading history, } \\
& \text { - } \quad \text { interference fit (percent squeeze), } \\
& \text { - } \quad \text { phase transitions. }
\end{aligned}
$$

Effect of Metal Constraint. Metal constraint had a pronounced effect on the thermal expansion of T-9B, T-7A, and TFM-1700. The effect was most noticeable for $\mathrm{T}-9 \mathrm{~B}$, which underwent contraction (annealing) in the free-standing, unconstrained case (Figure 4a), and incremental extrusion in the semitrapped, constrained case (Figure 4b). Further inspection of Figures $4 \mathrm{a}$ and $4 \mathrm{~b}$ shows that the largest change in TMA deflection occurred between the first and second heatings. For example, T-9B underwent a 1.2 percent axial contraction between the first and second heatings, indicative of T-9B's poor dimensional stability. To simulate multiple thruster firings, a constrained T-9B specimen was subjected to 50 thermal cycles. Incremental extrusion was still observed after the $50^{\text {th }}$ heating (data not shown). The total extrusion after 50 heatings was almost $500 \mu \mathrm{m}$ (0.020 in.). Even if shape and size differences between a TMA specimen and a PRCS pilot seal are taken into account, it can still be argued that repetitive 
thermal cycling of pilot seals may cause significant extrusion without the intervening influence of oxidizer or FORP.

Comparison of Figures $4 \mathrm{a}$ and $4 \mathrm{~b}$ also revealed a slight shift in the onset of the triclinic to hexagonal phase transition. The onset of this phase transition occurred at about $19^{\circ} \mathrm{C}\left(66^{\circ} \mathrm{F}\right)$ in the unconstrained case, consistent with the literature. ${ }^{2}$ In the constrained case, the onset occurred at slightly higher temperature, and was noticeably dampened. Since the phase transition originates from molecular relaxation within the crystalline phase, a shift towards higher temperature, coupled with dampening, suggests reduced crystalline mobility.

Effect of Thermal Cycling. The effect of thermal cycling on the CTE of constrained T-9B is shown in Figure 5. A line denoting the CTE $(=1.21 \times$ $\left.10^{-6}{ }^{\circ} \mathrm{C}^{-1}\right)$ of unconstrained T-9B is shown for comparison. All CTEs were measured at $71^{\circ} \mathrm{C}(160$ ${ }^{\circ} \mathrm{F}$ ). Constrained CTEs were corrected for $\mathrm{C} 455$ expansion. The data in Figure 5 show that the apparent $\mathrm{CTE}$ of constrained $\mathrm{T}-9 \mathrm{~B}$ was greater than that of unconstrained T-9B due to superposition of extrusion with unconstrained expansion. Also, the CTE of constrained T-9B decreased with each heating, approaching the CTE of unconstrained T-9B. The observation of decreasing CTE during successive heatings suggests that relief of internal stress introduced during interference fitting may be operative.

Effect of Resin Type. TMA results on T-9B are presented mainly for purposes of illustration. Of concern was whether T-7A, the material of choice used in PRCS pilot seal fabrication, behaved like T9B. The effects of metal constraint and thermal cycling on T-7A were thus determined. Because of problems associated with T-7A (room temperature phase transition, porous microstructure, cold flow, poor processibility), the effects of metal constraint and thermal cycling on replacement candidate Hostaflon TFM-1700 were also determined.

Figure 6 shows the effect of metal constraint on the permanent height change of as-received T-7A. Analogous data for T-9B and TFM-1700 are shown for comparison. The permanent height change was measured at $0{ }^{\circ} \mathrm{C}\left(32^{\circ} \mathrm{F}\right)$ prior to each heating. Constrained specimens (solid symbols) were subjected to a nominal 7 percent squeeze. Unconstrained specimens (open symbols) were free-standing. All specimens were thermally cycled from -15 to $45^{\circ} \mathrm{C}(5$ to $\left.113^{\circ} \mathrm{F}\right)\left(\Delta \mathrm{T}=60^{\circ} \mathrm{C}\left(108^{\circ} \mathrm{F}\right)\right)$. No attempt was made to correct the extrusion data for specimen size (percent squeeze), nor is it presently known if such a correction is warranted. Inspection of Figure 6 shows that the constrained expansion (extrusion) of T-7A and T-9B specimens was virtually the same (compare the solid diamonds and circles), and that the constrained expansion of TFM-1700 (solid triangles) was about twice that of T-9B or T-7A. Comparison of the unconstrained data (open symbols) showed that T-7A and TFM-1700 possessed superior dimensional stability compared to T-9B, which underwent permanent axial contraction (see Figure $4 \mathrm{a}$ also). The constrained data (solid symbols) in Figure 6 suggested that extrusion decreased in the order: TFM$1700>\mathrm{T}-7 \mathrm{~A} \approx \mathrm{T}-9 \mathrm{~B}$. Differences in the CTE and specimen size were too small to explain why TFM1700 extruded twice as much as T-7A or T-9B. For example, the CTE of TFM-1700 was found to be about 10 percent larger than that of T-7A (CTE $\left.2.06 \times 10^{-4}{ }^{\circ} \mathrm{C}^{-1}>\mathrm{CTE}_{\mathrm{T}-7 \mathrm{~A}}=1.89 \times 10^{-4}{ }^{\circ} \mathrm{C}^{-1}\right)$ Figure 7). Therefore, TFM-1700 should extrude only about 10 percent more than T-7A. Another explanation for the observed ranking could be the fact that TFMs have lower void content and are less compressible than PTFEs. ${ }^{5}$ Consequently, expansion of constrained TFM is expected to be fundamentally different from that of PTFE. However, other factors such as specimen-to-specimen variability could play a role. More data is needed before the reasons behind observed ranking in Figure 6 are firmly established. A comparison of the thermal expansion behavior of as-received T-7A and TFM-1700 over the normal PRCS thruster operational temperature range of 4 to $71^{\circ} \mathrm{C}\left(40\right.$ to $\left.160^{\circ} \mathrm{F}\right)$ is shown in Figure 7 . Each curve was the average of two specimens. The data were corrected for variation in initial specimen height. Aside from the CTE of TFM-1700 being greater than that of T-7A, TFM-1700 also exhibited the same room temperature phase transition as PTFE. Therefore, both TFM and PTFE are expected to undergo abrupt volume changes when thermally cycled in the vicinity of room temperature. Repeated excursions through this transition are expected to aggravate thermal extrusion.

Effect of $\Delta \mathrm{T}$. The maximum operational temperature limit during PRCS thruster firing is $80^{\circ} \mathrm{C}$ $\left(175^{\circ} \mathrm{F}\right)$, while the non-operational temperature limit during heat soak-back after firing is $110^{\circ} \mathrm{C}\left(230^{\circ} \mathrm{F}\right)$. These limits are rarely, if ever exceeded. Because PRCS pilot seals may experience many different temperature histories during service, the effect of $\Delta T$ on the extrusion of semitrapped PTFE was determined. Figure 8 shows the effect of thermal 
excursion $\left(\Delta T \mathrm{~s}=60,110\right.$, and $145^{\circ} \mathrm{C}(108,189$, and $\left.261^{\circ} \mathrm{F}\right)$ ) on the extrusion of semitrapped T-9B. Permanent extrusion was measured at $0^{\circ} \mathrm{C}\left(32^{\circ} \mathrm{F}\right)$ prior to each heating. The amount of permanent extrusion was found to increase with $\Delta T$, and was incremental. One feature not immediately apparent in Figure 8 was the exact dependence extrusion on $\Delta T$. If extrusion was linearly dependent on $\Delta T$, extrusion should increase as $1: 1.8: 2.4$ (with the $\Delta T$ ratio). If extrusion was linearly dependent on the time at temperature $(\Delta t-\Delta T)$, extrusion should increase as $1: 3.4: 5.8$ (with the $\Delta t-\Delta T$ ratio). However, the data showed that extrusion increased as 1:5.3:15.7 during the first heating, and as 1:4.6:13.4 during the tenth heating. Even if one corrects the $\Delta T$ or $\Delta t-\Delta T$ ratios for increasing thermal mismatch between the PTFE and $\mathrm{C} 455$, the permanent extrusion indicated in Figure 8 is too large to be predicted by either the temperature, or the time at temperature. One possible explanation for the departure of observed and predicted extrusion with increasing $\Delta T$ could be greater mobility of PTFE at higher temperature. Such mobility could be augmented relief of internal stress introduced during interference fitting.

Gap Formation. X-ray radiography of an extruded, semitrapped $\mathrm{T}-9 \mathrm{~B}$ specimen revealed the presence of a gap beneath the T-9B at the bottom of the cylindrical C455 cavity. The amount of the extrusion out of the cavity as measured by TMA was $540 \mu \mathrm{m}(0.0213 \mathrm{mil})$. The height of the gap inside the cavity measured by a probe difference method was $526 \pm 7 \mu \mathrm{m}(0.0207 \pm 0.003 \mathrm{mil})$. In other words, the extruded and gap volumes were essentially the same. A photograph showing the extruded T-9B specimen in question is shown in Figure 9. A positive print of the radiograph showing the location of the gap is shown in Figure 10. The gap shows up the off-white rectangle delimited at the bottom by the dark $\mathrm{C} 455$ base, and at the top by the gray PTFE cylinder. The observation of gaps formed solely as a consequence of thermal cycling conflicts with earlier claims attributing the gap formation to energetic reactions involving oxidizer or FORP. ${ }^{4}$

\section{Propellant Immersions}

One of the main arguments against thermal extrusion has been the lack of extrusion observed in oxidizer pilot seals. Baring differences due to evaporative cooling, the temperatures experienced by fuel and oxidizer pilot seals on the same thruster should be nearly the same. Consequently, there must be something unique to the oxidizer environment that makes oxidizer seals less prone to extrusion. Another possible explanation could be alteration of PTFE seal properties by oxidizer. To examine this possibility, parallel fuel-oxidizer immersions were conducted under hydrostatic conditions.

Since the immersions were conducted under hydrostatic, not differential pressure, the immersion tests also were not felt to be representative of actual PRCS service conditions. The effect of differential versus hydrostatic pressure on propellant uptake by PTFE however is not presently known.

Effect of Propellant on Mass Uptake and Swelling. PTFE and TFM exhibited negligible fuel uptake during series (T-9B) and parallel (T-7A and TFM-1700) immersions. In contrast, T-9B, T-7A, and TFM-1700 exhibited significant oxidizer uptake after hydrostatic immersions. For example, T-9B absorbed 5.1 percent oxidizer (w/w) after a 2 -week $71{ }^{\circ} \mathrm{C}$ $\left(160^{\circ} \mathrm{F}\right)$ Test 15 immersion. Leaving the T-9B in oxidizer for another week at room temperature revealed no further uptake, indicating equilibrium saturation had been reached. This is consistent with the work of other workers ${ }^{14}$ who observed that PTFE absorbed several percent (w/w) oxidizer.

Earlier results (Figure $4 \mathrm{a}$ ) showed axial contraction of $\mathrm{T}-9 \mathrm{~B}$ heated to $130^{\circ} \mathrm{C}\left(270^{\circ} \mathrm{F}\right)$. T-9B exhibited the same type of axial contraction during a 2-week $71^{\circ} \mathrm{C}\left(160^{\circ} \mathrm{F}\right)$ Test 15 fuel immersion. Measurement of specimen diameter showed that axial contraction was compensated by radial expansion, leading to no volume change within experimental error. In contrast, subsequent exposure of the T-9B specimens to oxidizer caused 5 percent increases in the length and diameter, indicating isotropic swelling.

Similar mass uptake was observed for oxidizer-exposed T-7A and TFM-1700, which absorbed 3.8 and 3.5 percent (w/w) propellant, respectively, after 7 -week room temperature exposures (Figure 11). The corresponding fuel uptake by T-7A and TFM-1700 after a 4-week room temperature exposure was negligible. Mass desorption measurements showed that about 20 percent of the oxidizer remained in T-7A and TFM-1700 one week after removal from oxidizer.

The mass uptake data (Figure 11) showed that PTFE and TFM had a higher affinity for oxidizer than fuel. Even in the absence of an external driving force such as differential pressure, oxidizer was readily incorporated into $\mathrm{T}-9 \mathrm{~B}, \mathrm{~T}-7 \mathrm{~A}$, and TFM-1700. The mass uptake data also showed that T-7A absorbed slightly more oxidizer than TFM-1700. 
Effect of Propellant on Modulus. PTFE is known to interact strongly, but reversibly with the polar molecule $\mathrm{NO}_{2}$, which is in equilibrium with $\mathrm{N}_{2} \mathrm{O}_{4} \cdot{ }^{14}$ Such interaction is expected to disrupt the attractive forces within PTFE, leading to decreased compressive strength and hardness. Accordingly, the effect of propellant exposure on the room temperature modulus of T-7A and TFM-1700 was determined using TMA (Table 4). Both constrained and unconstrained specimens were tested.

Table 4. The Effect of Propellant Exposure and Thermal Cycling on Room Temperature Modulus of PRCS Seal Material as Measured by TMA ${ }^{\mathrm{a}}$

\begin{tabular}{|c|c|c|c|c|c|}
\hline \multirow{3}{*}{$\begin{array}{l}\text { Exposure } \\
\text { Liquid }^{\text {b }}\end{array}$} & \multirow[b]{3}{*}{ Modulus $^{\mathrm{c}}$} & \multicolumn{4}{|c|}{ Material } \\
\hline & & \multicolumn{2}{|c|}{ Teflon-7A } & \multicolumn{2}{|c|}{ TFM-1700 } \\
\hline & & uncon. & constr. & uncon. & constr. \\
\hline \multirow[t]{2}{*}{ Unexposed } & $\mathrm{E}_{\text {initial }}$ & 50 & 221 & 56 & ND \\
\hline & $E_{\text {final }}$ & 81 & 230 & 64 & ND \\
\hline \multirow[t]{2}{*}{ Fuel } & $\mathrm{E}_{\text {initial }}$ & 67 & 196 & 28 & 96 \\
\hline & $E_{\text {final }}$ & 80 & 233 & 39 & 214 \\
\hline \multirow[t]{2}{*}{ Oxidizer } & $\mathrm{E}_{\text {initial }}$ & 19 & 194 & 27 & 133 \\
\hline & $E_{\text {final }}$ & 28 & 208 & 41 & 156 \\
\hline \multicolumn{6}{|c|}{$\begin{array}{l}\text { Abbreviation used: ND (not determined), uncon. (unconstrained), } \\
\text { constr. (constrained). }\end{array}$} \\
\hline \multicolumn{6}{|c|}{$\begin{array}{l}{ }^{\mathrm{b}} \text { Exposures were for } \geq 2 \text { weeks at ambient temperature and pressure } \\
\text { (hydrostatic). }\end{array}$} \\
\hline \multicolumn{6}{|c|}{$\begin{array}{l}{ }^{\mathrm{C}} \text { Units are in } \mathrm{MPa}, \mathrm{E}_{\text {initial }} \text { and } \mathrm{E}_{\text {final }} \text { measured before } 1^{\text {st }} \text { and } 5^{\text {th }} \text { heat } \\
\text { cycles, respectively. }\end{array}$} \\
\hline
\end{tabular}

The above modulus data showed that constrained specimens were generally harder than unconstrained, free-standing specimens. While higher moduli were in part attributable to the pressure applied to the top of each specimen to force them into the metal bore during constrained specimen preparation, the nominal 7 percent squeeze used could also be a factor. Oxidizer exposure caused measurable softening of unconstrained specimens. In fact, the lowest modulus observed (19 $\mathrm{MPa})$ was for unconstrained, oxidizer-exposed T-7A. The modulus decrease of constrained, oxidizer-exposed specimens was not nearly as pronounced (see the Teflon-7A, constr. column). The effect of fuel exposure was harder to interpret, since both decreases and increases in the modulus were observed. Last, the data showed that PTFE and TFM specimens harden after thermal cycling, regardless of prior propellant exposure or metal constraint (compare $\mathrm{E}_{\text {initial }}$ and $\mathrm{E}_{\text {final }}$ values).

\section{Impression Replicas of Representative Pilot Seats}

The extrusion of several representative pilot seats suspected of extrusion due to poor ATP response times was measured using an impression casting technique. Both proud and retainer heights were measured (Table 5). The proud height corresponds to the height of the seal above the metal seat as measured at the seal's inner circumference, while the retainer height corresponds to the height of the seal above the metal retainer as measured at the seal's outer circumference. Pilot seals from fuel valve $\mathrm{S} / \mathrm{Ns} 254$, 553,580 , and 806 exhibited loaded extrusion, while seals from fuel valve S/Ns 637 and 679 exhibited unloaded extrusion (Tables 1 and 2). Comparison of the proud height determined using the impression replica technique (next to last column in Table 5) with the amount of extrusion predicted using the WSTF Poppet Lift test (last column in Table 1 and 2) gave good agreement.

As a control, impression replicas were taken of several pilot seats that had never seen mission service. They were: 1) seat S/N 152 exposed to a controlled 3-month thermal $\left(21-38^{\circ} \mathrm{C}\left(70-100^{\circ} \mathrm{F}\right)\right)$ and oxidizer vapor (15-53 psia)) exposure at WSTF, 2) seat $S / N 2054$ that had undergone pure thermal extrusion due to excessive heat soak-back during a WSTF Depot lock-collar weld procedure (PRCS fuel valve refurbishment), and 3) unused, unloaded seat S/N 3203.

Representative photographs of PRCS seat assemblies showing loaded and unloaded extrusion are shown in Figures 16, along with a control of PRCS seat assembly showing no extrusion. Both loaded and unloaded extrusion cases show outwardly angled protrusion (splay) caused by poppet action and/or unconstrained lateral thermal expansion. The observation of splay supports the notion that the pilot seal could become pinned during cooling, thus preventing complete recovery and subsequently creating a state of tensile stress in the vertical leg of the pilot seal. Notice also what appears to be scalloping along the inner circumference (proud height) edge of S/N 254. It is presently unknown whether such scalloping is normal, or is indicative of large thermal excursions during mission service or ground turnaround. 
The impression replica of unused seat assembly S/N 3203 shows a noticeable lack of coining, indicative of the seal's unused condition. The impression replica (not shown) of seat S/N 2054 (proud height $=105 \mu \mathrm{m}$ (0.0065 in.); retainer height $=207 \mu \mathrm{m}(0.0127 \mathrm{in})$.$) indicated extrusion of$ comparable magnitude to that noted for extruded Orbiter seals. This indicates that an isolated thermal event (heat soak-back during retainer welding) in the absence of oxidizer or FORP is capable of causing significant extrusion.

\section{CONCLUSIONS}

Both model and experimental data showed that extrusion could be caused by thermal cycling alone, without the intervening presence of oxidizer or FORP. Model results were in good agreement with impression replica data on thermally extruded seats, suggesting that differential thermal expansion is a contributing factor in PRCS fuel valve seal extrusion. TMA data on metal-constrained PTFE and TFM specimens simulating a PRCS FPOV configuration showed that extrusion caused by thermal cycling is incremental, irreversible, and increases with the size of the thermal excursion. X-ray radiography further showed that thermal extrusion is accompanied by gap formation. Mass uptake and swelling data show that PTFE and TFM have a higher affinity for oxidizer than fuel. Corresponding TMA data showed differences in the effect of oxidizer versus fuel on seal properties: for example, oxidizer exposure was found to lead to decreased modulus, measurable contraction after heating, and a shift in room temperature phase transition of constrained PTFE to higher temperature. Last, the thermomechanical behavior of Hostaflon TFM-1700 was found to be similar to that of Teflon $7 \mathrm{~A}$ PTFE, suggesting the TFM may not be a viable replacement material for pilot poppet POV sealing applications involving repetitive thermal cycling. While the data presented in this study does not refute the possibility of oxidizer-induced extrusion, arguments discounting the possibility of thermal extrusion are diminished.

Calculations of the energy, heat or gas release from reactions of oxidizer or FORP with fuel at or near the fuel pilot seal showed that component damaging events are plausible. However, no direct link was established between seal extrusion and the presence of oxidizer or FORP that was both quantifiable and unambiguous. The heat, energy, or gas release associated with presumed oxidizer or
FORP reactions has never been detected or measured. Either the reaction(s), do not occur, are too transient, or occur too far away from the nearest PRCS thermocouple and transducer to be detected.

The presence of oxidizer vapor at or near the fuel valve pilot seal during periods of ground turnaround is nonetheless considered problematic. Oxidizer leakage and subsequent vapor build-up inside PRCS thruster chambers should be minimized if not altogether eliminated regardless of the ultimate mechanism(s) proven to be responsible for fuel valve pilot seal extrusion.

\section{ACKNOWLEDGEMENTS}

The authors gratefully acknowledge Dr. Dennis Davis for helpful discussions on FORP thermochemistry; Brian Ross, Terrence Kelly, and Don Gonzalez for providing guidance and information on PRCS thruster operation, maintenance, and service history; and Sergio Rojas, Brooks Wolle and Paul Spencer for immersion testing, x-ray radiography, and impression replica work. 


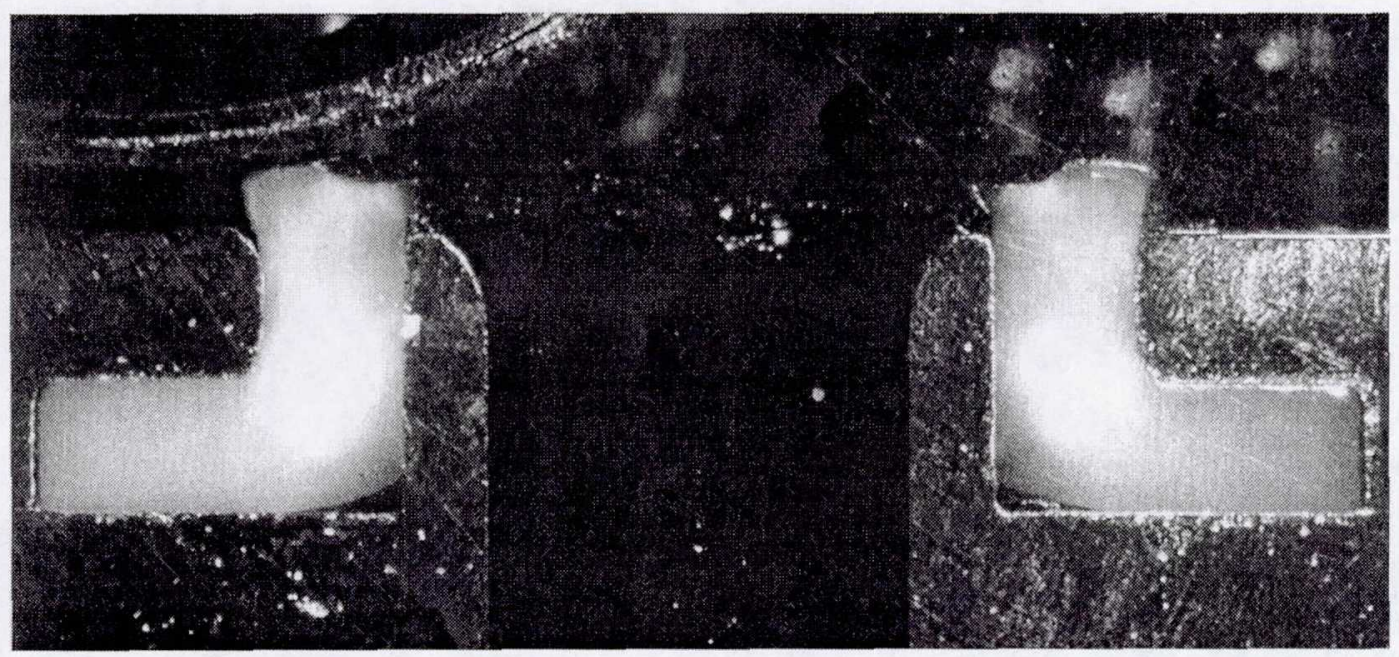

Figure 1. Cross-Section of Fuel-Valve S/N 530 Pilot Seat As Seen Under Optical Magnification (NOTE: Gaps appear under the vertical leg of the seal, and to the left and right of the horizontal leg of the seal.)
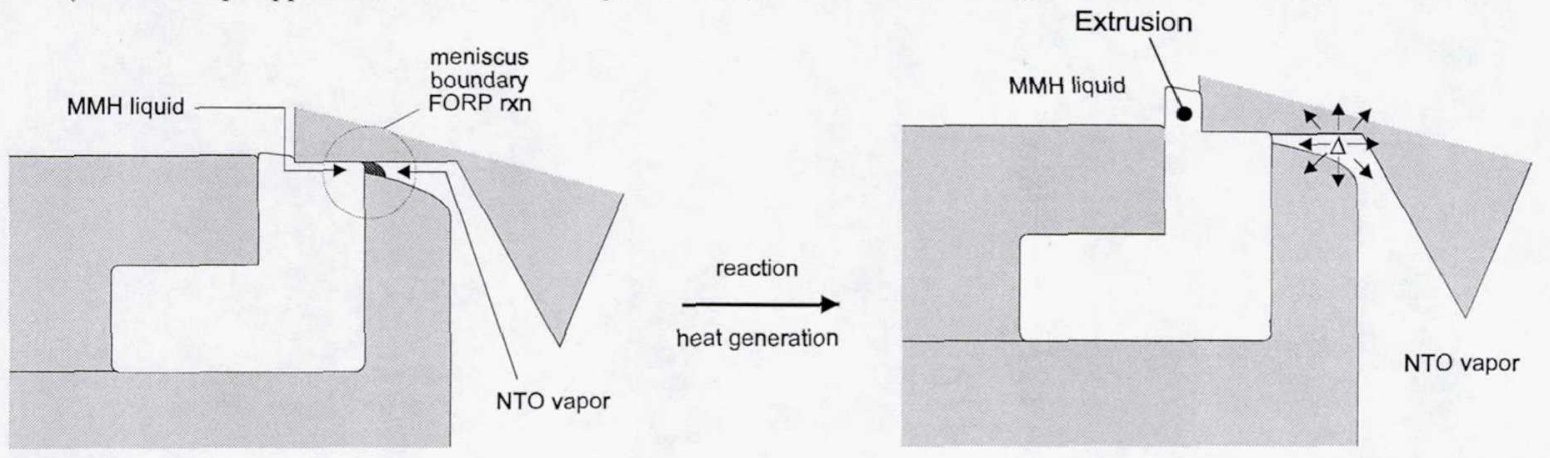

Figure 2. Diagram showing a fuel-oxidizer reaction at a fuel meniscus downstream of the PRCS pilot seal

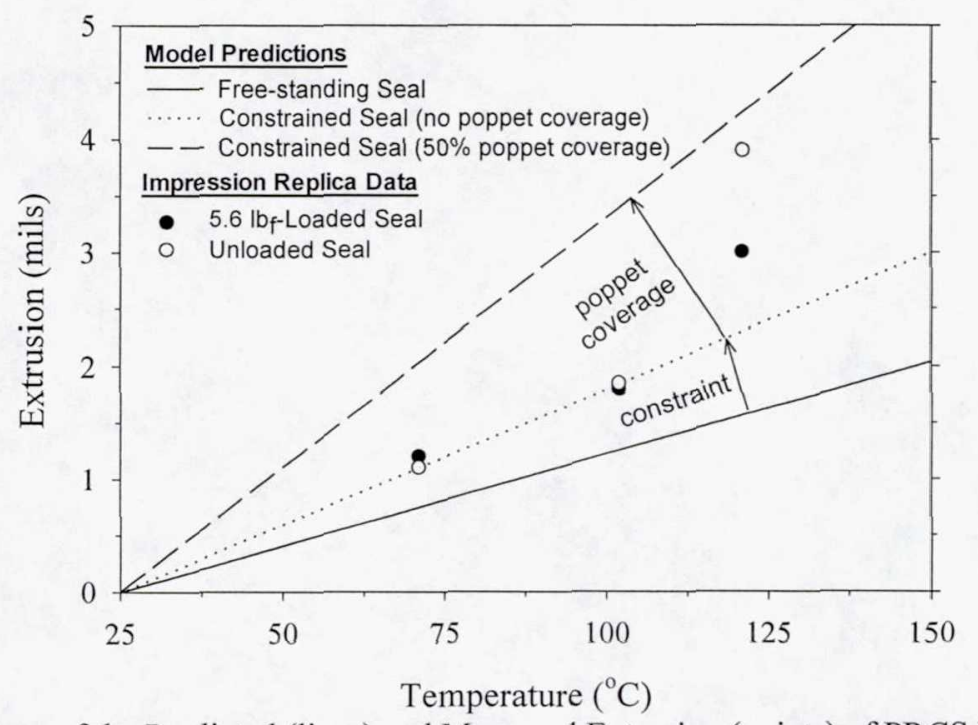

Figure 3. Comparison of the Predicted (lines) and Measured Extrusion (points) of PRCS Pilot Seals as a Function of Temperature (Extrusion Normalized to $25^{\circ} \mathrm{C}$ )

14

American Institute of Aeronautics and Astronautics 


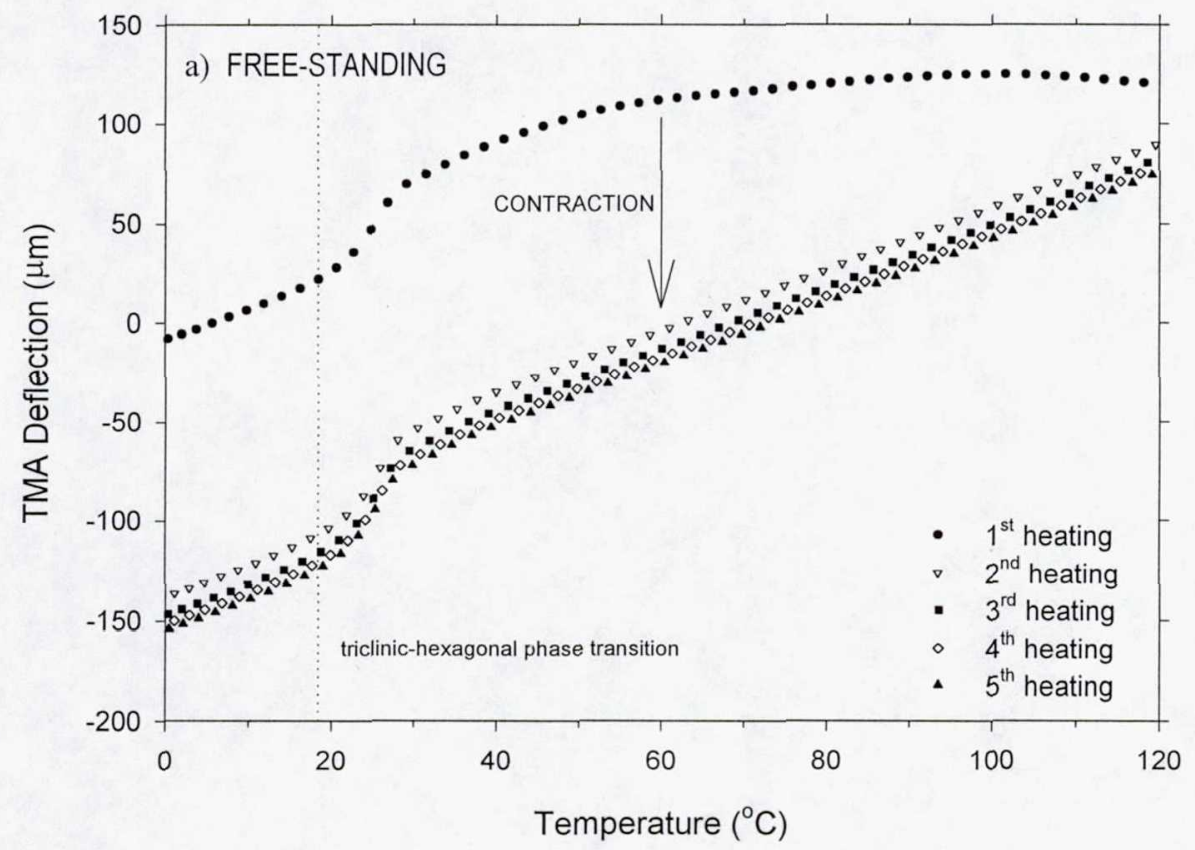

(a)

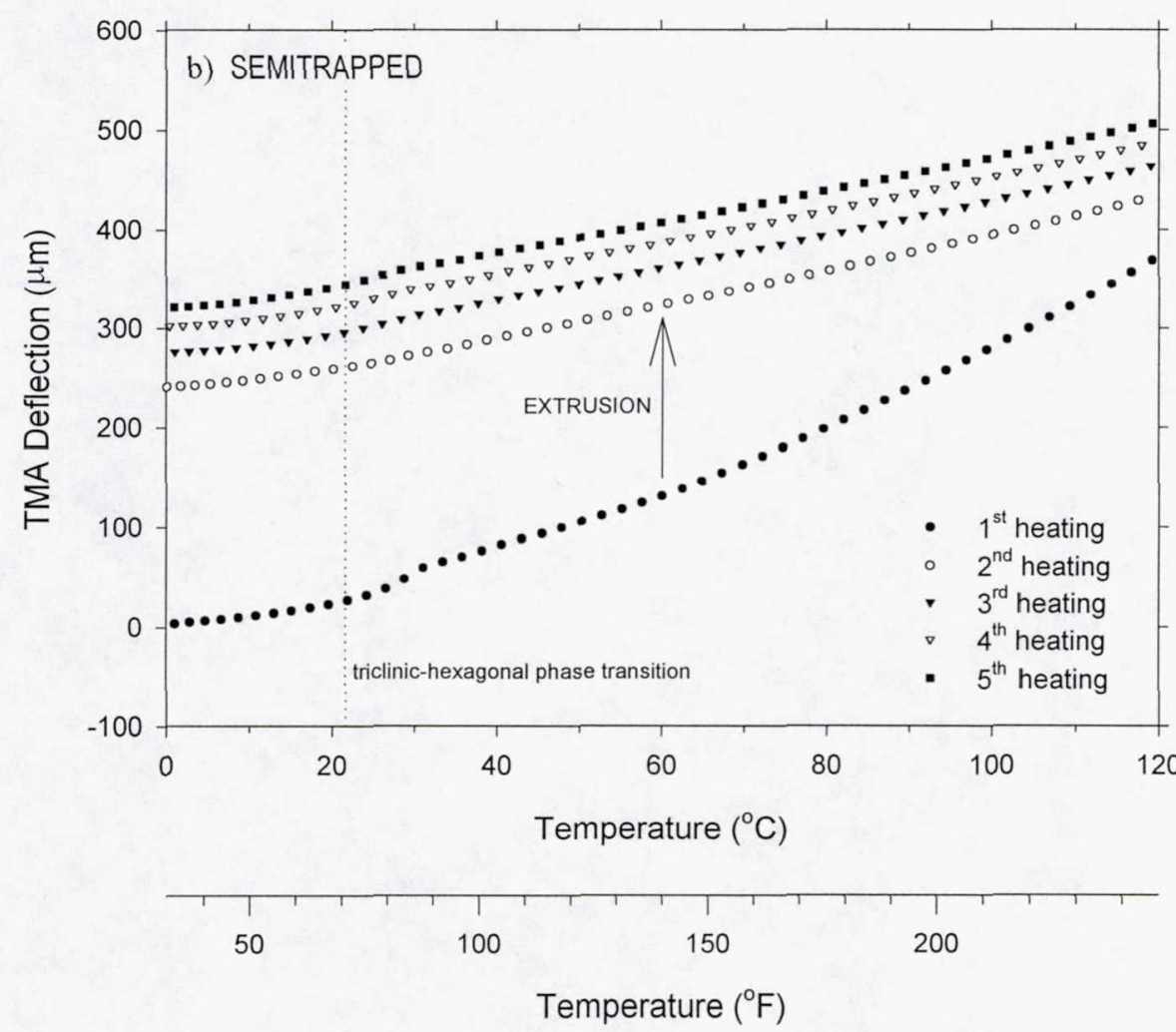

(b)

Figure 4. Plots Showing the Effect of Thermal Cycling from -15 to $130^{\circ} \mathrm{C}\left(5\right.$ to $\left.266^{\circ} \mathrm{F}\right)$ on the Dimensions of a) Free-Standing (Unconstrained), and b) Semitrapped (Constrained) Teflon 9B Specimens 


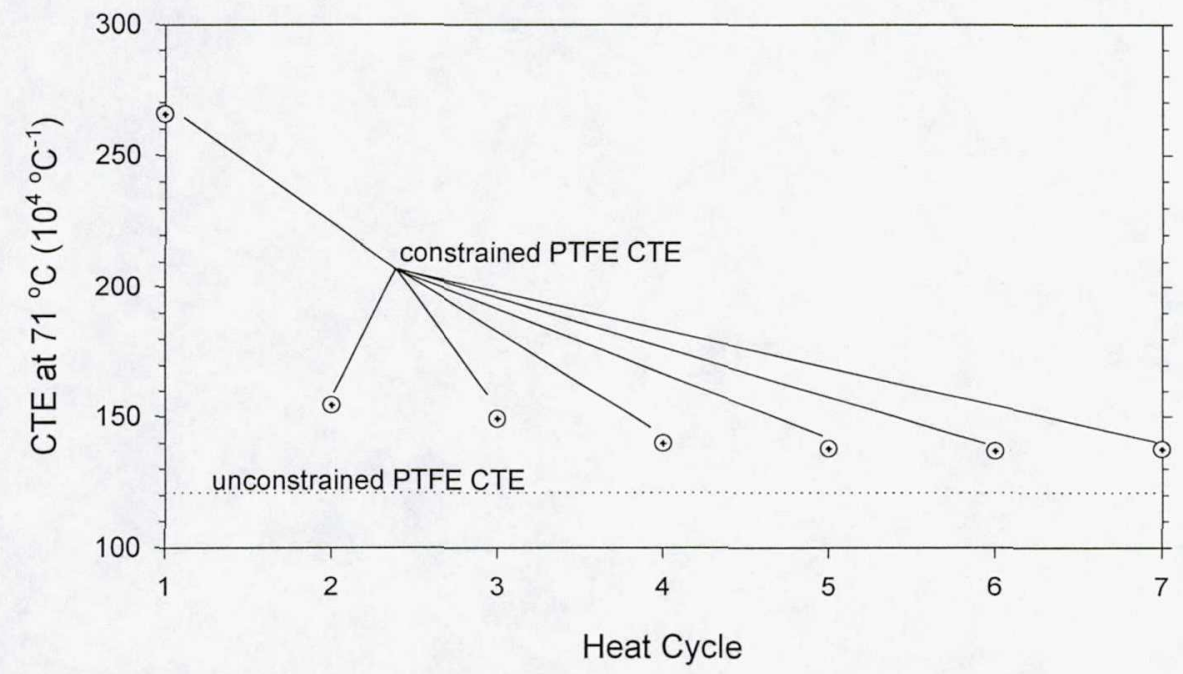

Figure 5. Effect of Thermal Cycling on the Coefficient of Thermal Expansion (CTE) of Constrained Teflon 9B; the Reference Line Shows the CTE of Unconstrained Teflon 9B for Comparison (NOTE: Specimens were cycled between 20 and $130^{\circ} \mathrm{C}\left(68\right.$ and $\left.\left.266^{\circ} \mathrm{F}\right)\right)$

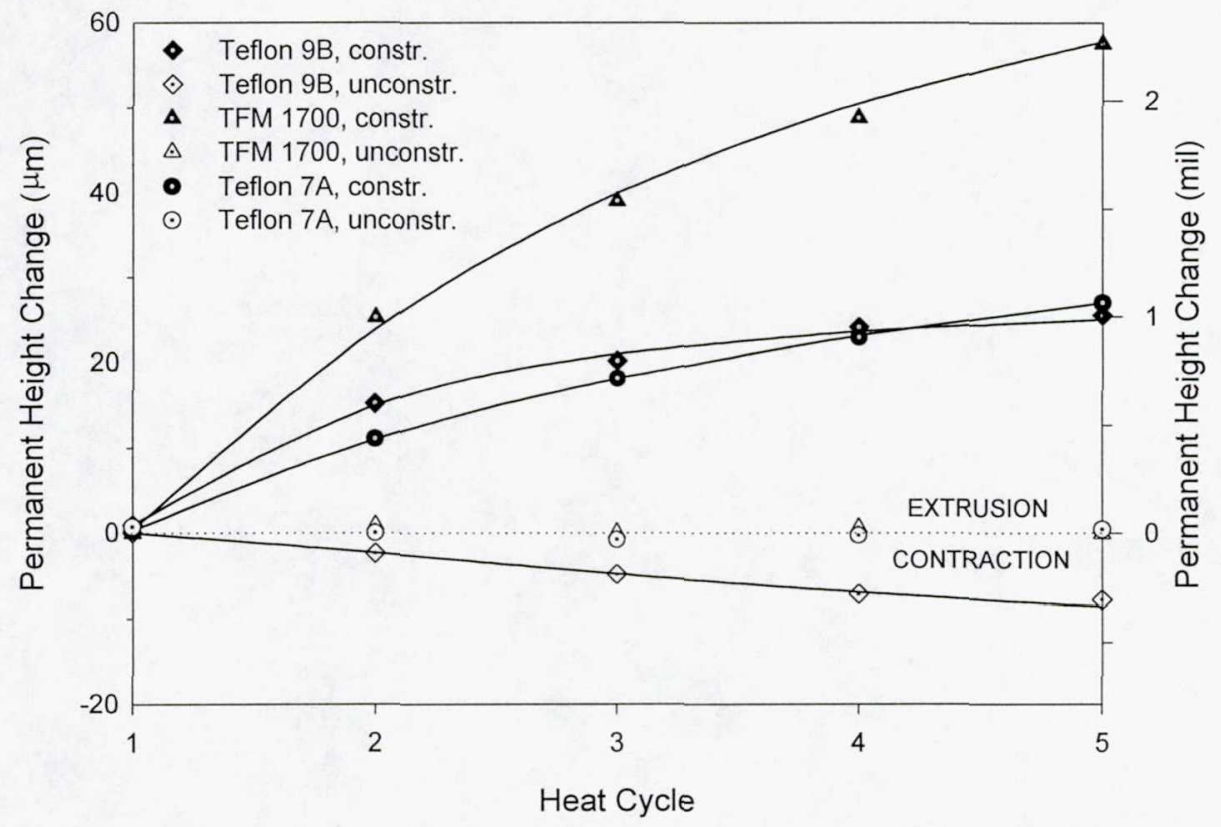

Figure 6. Effects of Thermal Cycling and Metal Constraint on the Permanent Height Change of As-Received Teflon 9B, Teflon 7A, and Hostaflon TFM-1700

(NOTE: specimens were cycled between -15 and $45^{\circ} \mathrm{C}\left(5\right.$ and $\left.\left.113^{\circ} \mathrm{F}\right)\right)$ 


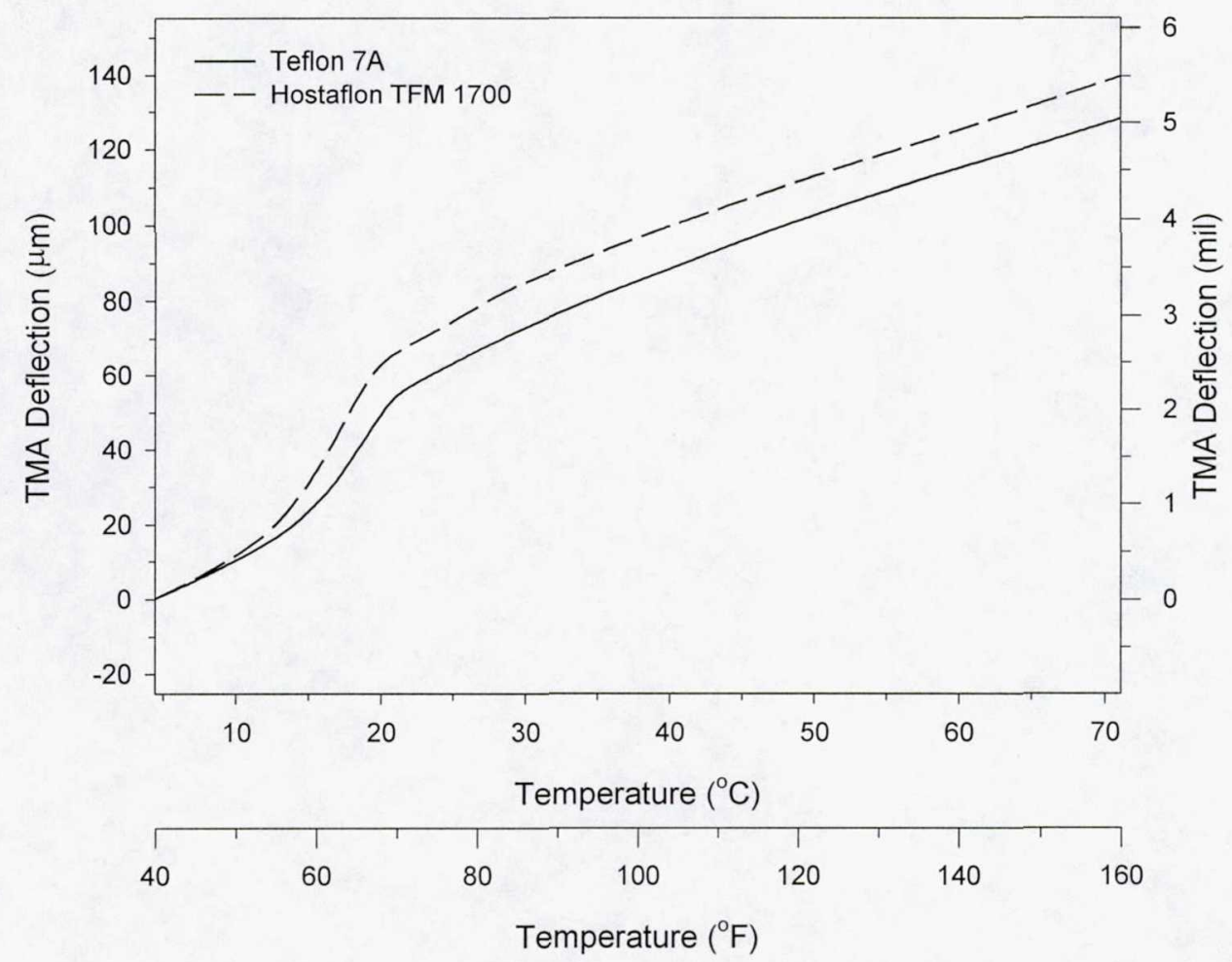

Figure 7. Comparison of the Thermal Expansion of As-Received, Free-Standing TFM-1700 (Dashed Curve) with Teflon 7A PTFE (Solid Curve) Over the PRCS Thruster Operational Temperature Range (NOTE: Average specimen height was $12.7 \mathrm{~mm}(0.500 \mathrm{in})$.

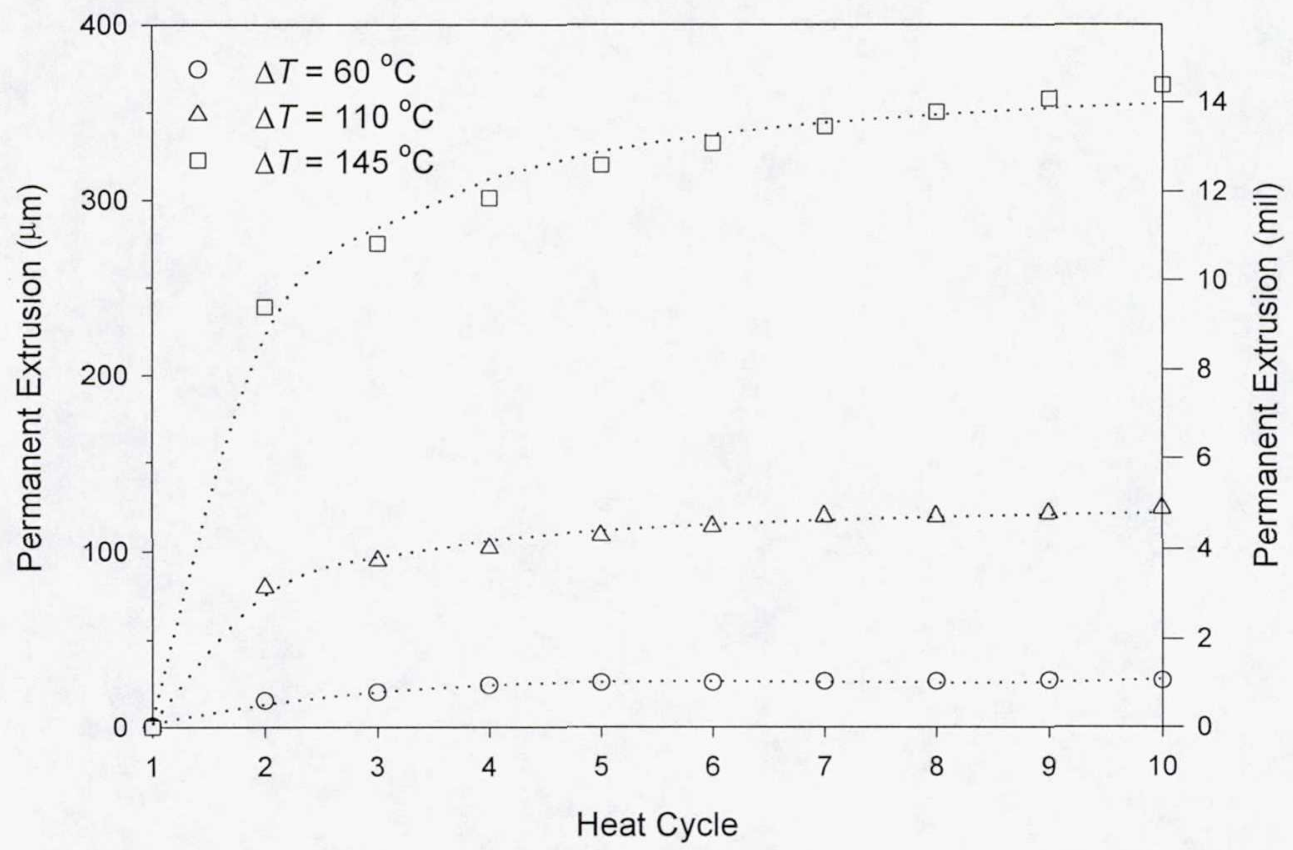

Figure 8. Plot Showing the Effect of $\Delta \mathrm{T}$ on the Extrusion of a Semitrapped Teflon 9B PTFE Cylinder inside a Custom 455 Metal Sleeve

17

American Institute of Aeronautics and Astronautics 


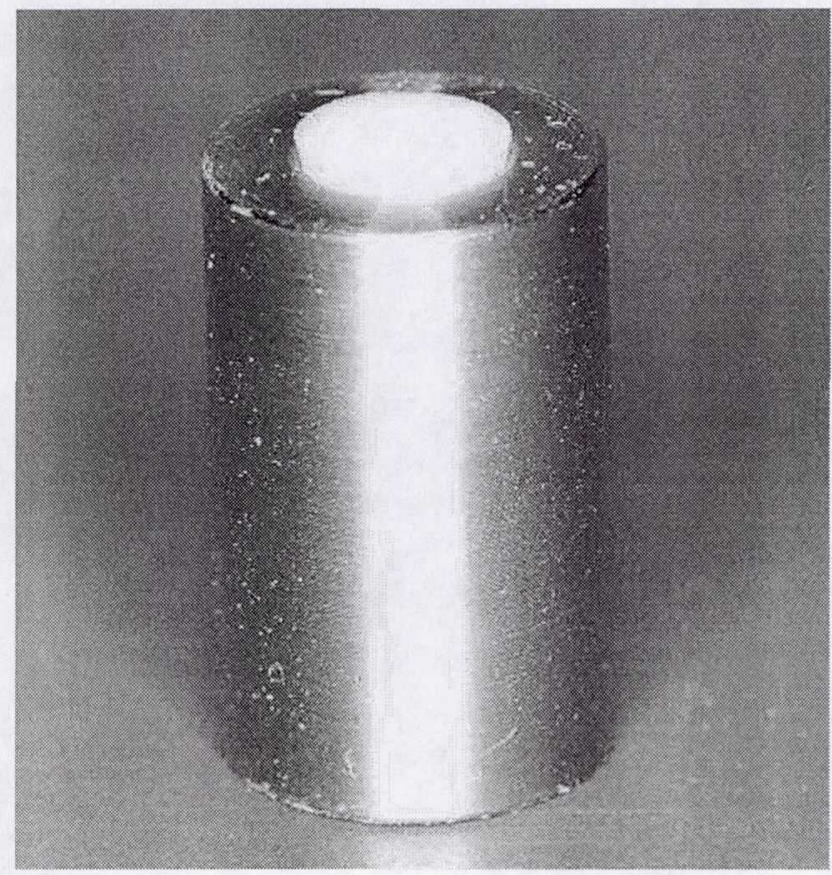

Figure 9. Custom 455 Cylinder with an Extruded, Semitrapped Teflon 9B PTFE Specimen

(NOTE: Thermal cycling resulted in $540 \mu \mathrm{m}(0.021 \mathrm{mil})$ extrusion of the PTFE out of the cavity.)

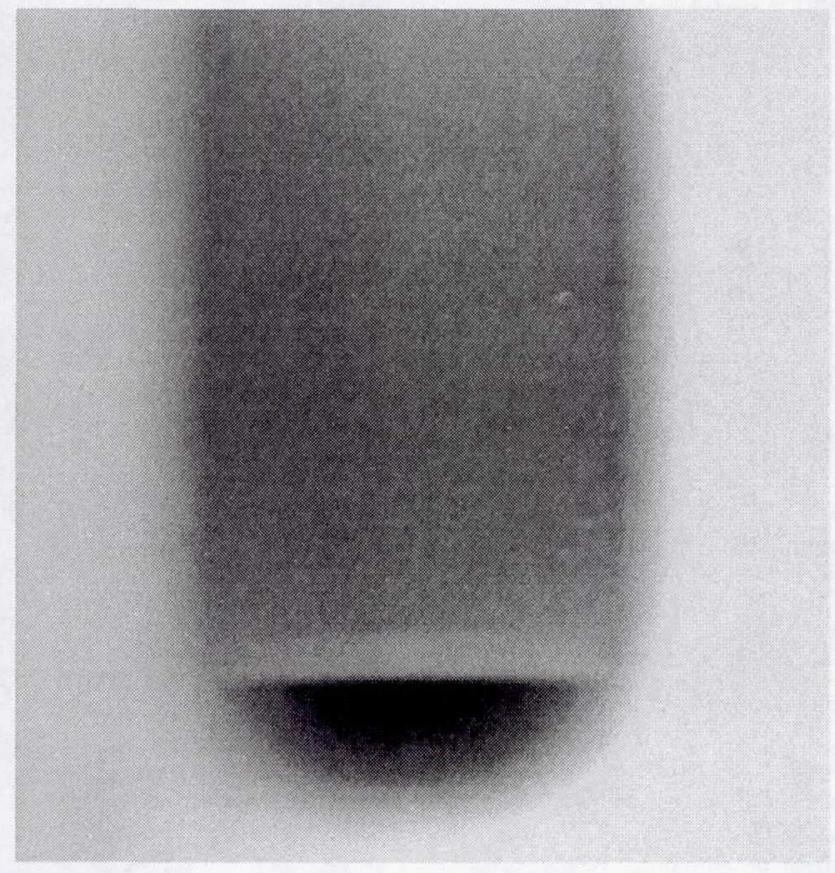

Figure 10. A Positive Print of an x-ray Radiograph of an Extruded, Semitrapped Teflon 9B PTFE Specimen inside a Custom 455 Metal Cavity

(NOTE: Thermal cycling resulted in formation of a gap with a height of $526 \pm 7 \mu \mathrm{m}(0.0207 \pm 0.003 \mathrm{mil})$

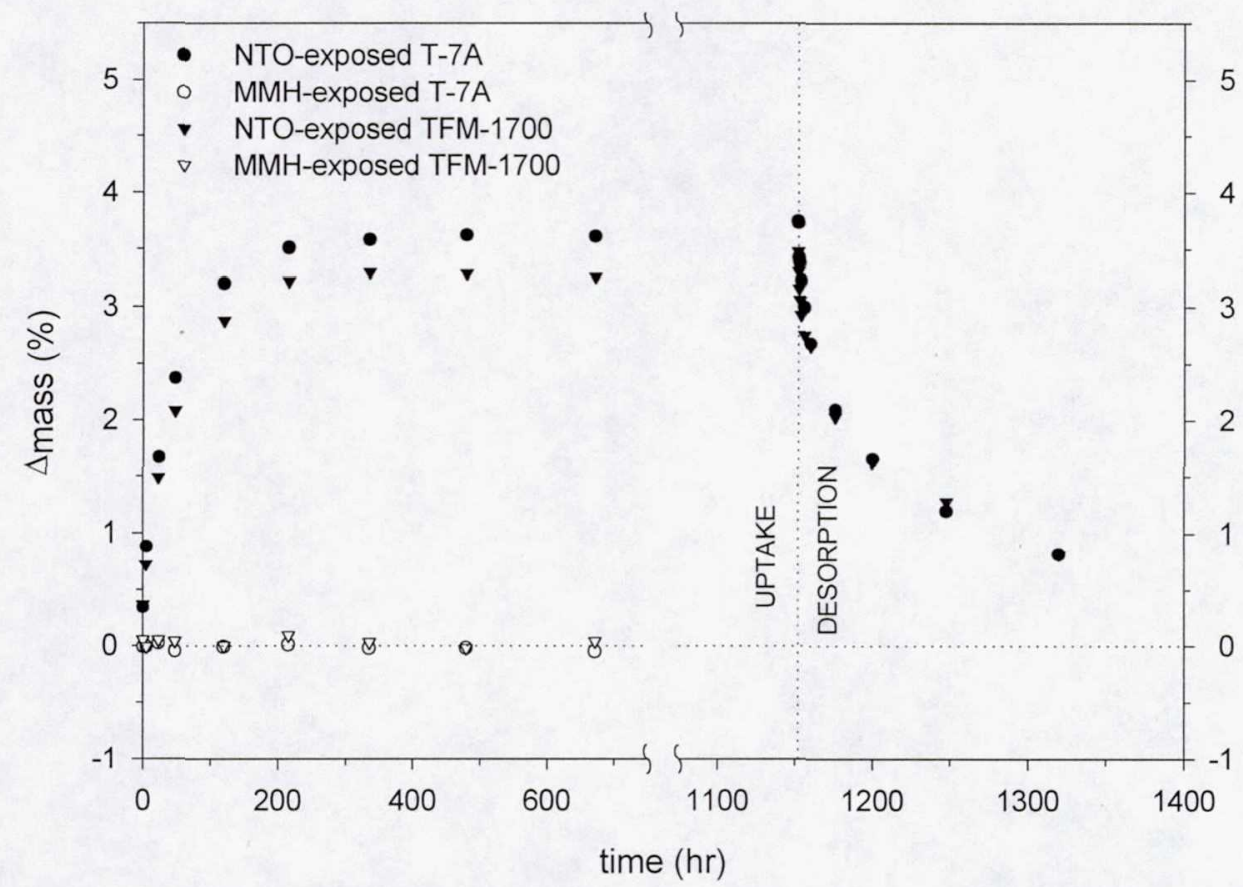

Figure 11. Mass Uptake and Desorption Data for Teflon 7A (Circles) and TFM-1700 (Triangles)

(NOTE: Mass uptake measurements were made for oxidizer (7-week data, solid symbols) or fuel (4-week data, open symbols), after which oxidizer desorption measurements were made (1-week data).) 
Table 5. PRCS Pilot Operated Valve Seat ${ }^{a}$ Impression Replicas ${ }^{b}$

\begin{tabular}{|c|c|c|c|c|c|}
\hline $\begin{array}{l}\text { Valve } \\
\text { S/N }\end{array}$ & $\begin{array}{l}\text { Seat } \\
\text { S/N }\end{array}$ & $\begin{array}{l}\text { Valve Type } \\
\text { and Origin }\end{array}$ & $\begin{array}{l}\text { Extrusion } \\
\text { Type }\end{array}$ & $\begin{array}{l}\text { Proud Height } \\
\text { mil }(\mu \mathrm{m})\end{array}$ & $\begin{array}{l}\text { Retainer Height } \\
\text { mil }(\mu \mathrm{m})\end{array}$ \\
\hline 254 & 3040 & fuel, Orbiter & loaded & $9.3(235)$ & $18.1(460)$ \\
\hline 553 & 3386 & fuel, Orbiter & loaded & $4.1(165)$ & $8.1(322)$ \\
\hline 580 & 1305 & fuel, Orbiter & loaded & $7.6(194)$ & $11.9(303)$ \\
\hline 806 & 3372 & fuel, Orbiter & loaded & $7.3(185)$ & $13.9(353)$ \\
\hline 637 & 2040 & fuel, Orbiter & unloaded & $1.7(43)$ & $10.1(256)$ \\
\hline 679 & 2026 & fuel, Orbiter & unloaded & $2.0(50)$ & $10.0(254)$ \\
\hline As-built ${ }^{\mathrm{c}}$ & 152 & fuel, control & unloaded & $1.0(25)$ & $4.8(121)$ \\
\hline As-built ${ }^{\mathrm{c}}$ & 2054 & fuel, Depot ${ }^{d}$ & pure thermal & $6.5(105)$ & $12.7(207)$ \\
\hline As-built ${ }^{\mathrm{c}}$ & 3203 & unused, control & not extruded & $\mathrm{ND}^{\mathrm{e}}$ & $\mathrm{ND}^{\mathrm{e}}$ \\
\hline \multicolumn{6}{|c|}{${ }^{\mathrm{a}}$ Seats were manufactured by Kaiser Marquardt (P/N 235681 or $\left.234158-504\right)$} \\
\hline \multicolumn{6}{|c|}{${ }^{\mathrm{b}}$ Replicas made using Reprorubber Thin Pour \#16135 } \\
\hline \multicolumn{6}{|c|}{ As-received valve seats had no associated valve $\mathrm{S} / \mathrm{N}$} \\
\hline \multicolumn{6}{|c|}{ d Extruded during WSTF Depot lock collar weld procedure. } \\
\hline \multicolumn{6}{|c|}{${ }^{\mathrm{e}} \mathrm{ND}=$ not determined; as-built, unextruded seal. } \\
\hline
\end{tabular}
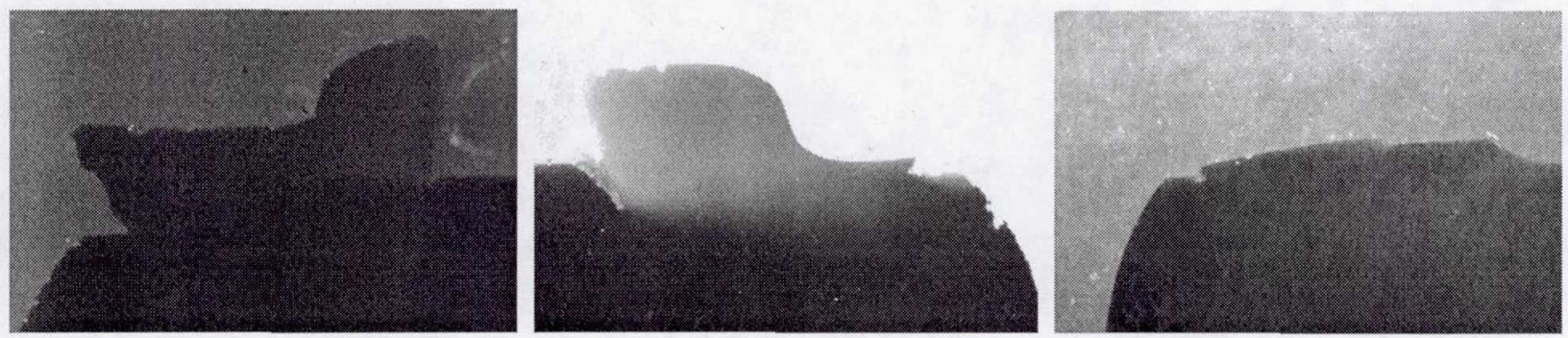

Figure 16. Impression Replicas of Orbiter PRCS a) Thruster S/Ns 254 (Loaded Extrusion), b) Thruster S/Ns 637 (Unloaded Extrusion), and 3) an unused pilot seal with no extrusion or coining (Seat S/N 3203) $(63 \times$ Magnification) 


\section{REFERENCES}

1. Litwinski, J., D. Sueme, D., and Wittman,. C. Failure Investigation of RCS Fuel Valve Extruded Teflon Seals. M\&P Engineering Report 59652007, Rockwell International, Materials \& Process Engineering Laboratories, Downey, CA, April 1996.

2. Sperati, C. A. Physical Constants of Fluoropolymers. Polymer Handbook, Brandrup, J., Immergut, E. H., Eds., Wiley-Interscience, Chap. V, 36 (1989).

3. Carpenter Technology Corporation. Carpenter Stainless Steels. Reading, PA, 192, 1991.

4. Ross, B., R. Lynch, R., and Pfeifer, G. RA24(R) Failure Analysis Report, Primary Thruster $S / N$ 325 Failed Off During STS-68. WSTF-PT-FAR003, NASA Johnson Space Center White Sands Test Facility, Las Cruces, NM, September 29, 1995.

5. Hoechst Aktiengesellschaft. Hostaflon TFM, The 2nd PTFE Generation (Product literature). Kelsterbach, Germany, January 1996.

6. Material Specification MMS 2517, Revision B, Polytetrafluoroethylene Bar, The Marquardt Company, Van Nuys, CA, January 1991.

7. Aerospace Material Specification 3660, Revision C. Polytetrafluoroethylene (PTFE) Moldings, General Purpose Grade, As Sintered. Society of Aerospace Engineers, Warrendale, PA, February 1994.

8. Waller, J. M., Investigation of Probable Factors Contributing to the Extrusion of Monomethylhydrazine Pilot Operated Valve Seats, NASA-JSC Test Report TR-960-001, White Sands Test Facility, Las Cruces, NM, in review.

9. NASA-STD-6001. "Reactivity' of Materials in Aerospace Fluids (Test 15)" (Chapter 4, Section 4.15), in Flammability, Odor, Offgassing, and Compatibility Requirements and Test Procedures for Materials in Environments that Support Combustion. Office of Safety and Mission Quality, February 1998.
10. Miron, Y., Perlee, H. E. The Hard Start Phenomena in Hypergolic Engines Volume III. Physical and Combustion Characteristics of Engines Residues. Pittsburgh Mining and Safety Research Center, Interim Report No. 1646. NASA Lyndon B. Johnson Space Center, Houston TX, March 22, 1974.

11. Davis, D. D., Dee, L. A., and Beeson, H. D. "Chemical Characterization and Reactivity of Fuel-Oxidizer Reaction Product." Paper presented at the 1997 JANNAF PDSC SEPS Joint Meeting, Sunnyvale, CA, March 17-20, 1997, Vol. 1, p. 397.

12. Seamans, T. F., Dawson, B. E. Hypergolic Ignition at Reduced Pressures. AFRPL-TR67129, June 1967.

13. Albright, J. POV Seat Thermal Cycle Test Report, NASA Johnson Space Center, Houston, TX, July 25, 1995.

14. Pasternak, R. A., Christensen, M. V., and Heller, J. "Diffusion and Permeation of Oxygen, Nitrogen, carbon Dioxide, and Nitrogen Dioxide through Polytetrafluoroethylene." Macromolecules, 3, 366 (1970). 